\title{
Pragmatics and the grammar of anaphora: a partial pragmatic reduction of Binding and Control phenomena ${ }^{1}$
}

\author{
STEPHEN C. LEVINSON \\ Department of Linguistics, University of Cambridge
}

(Received io April 1987)

The properties of gaps are intrinsically significant in that the language learner can confront little direct evidence bearing on them, so that it is reasonable to assume that they reflect deeper principles of UG, the biologically determined endowment that will be the primary concern for those interested more in the nature of the human mind than in the arrangement of data in the environment (Chomsky, 1982:19. Some concepts and consequences of the theory of Government and Binding).

\section{LIMITATIONS}

Anaphora is the phenomenon whereby one linguistic element, lacking clear independent reference, can pick up reference through connection with another linguistic element. Stated thus it is obvious that anaphora is perhaps primarily a semantic and pragmatic matter - and especially a pragmatic

[1] This paper is one in a series that develops a pragmatic framework in loose confederation with Jay Atlas and Larry Horn: thus they may or may not be responsible for the ideas contained herein. Jay Atlas provided many comments which I have utilized or perverted as the case may be. The Australian data to which this framework is applied was collected with the financial and personal assistance of many people and agencies acknowledged separately below; but I must single out for special thanks John Haviland, who recommended the study of Guugu Yimidhirr anaphora to me and upon whose grammatical work on Guugu Yimidhirr this paper is but a minor (and perhaps flawed) elaboration. A grant from the British Academy allowed me to visit Haviland in September 1986 to discuss many aspects of Guugu Yimidhirr with him, and I am most grateful to the Academy for funding this trip and to Haviland for generously making available his time, his texts (from which I have drawn many examples, not always with specific acknowledgement) and most especially his expertise. Where I have diverged from his opinion I may well learn to regret it. I must also thank Nigel Vincent for putting me in touch with a number of recent relevant developments in syntax (only some of which I have been able to address) and for suggestions for numerous improvements. In addition, I have benefited immensely for comments on a distinct but related paper (Levinson, 1987) kindly provided by Jay Atlas, John Haviland, John Heritage, Phil Johnson-Laird, John Lyons, Tanya Reinhart, Emanuel Schegloff and an anonymous referee; and from comments on this paper by participants in the Cambridge Linguistics Department seminar where it was first presented (especial thanks to John Lyons and Huang Yan for further comments, and Mary Smith for a counter-example). Despite all this help, there are sure to be errors of data and analysis that I have persisted in. Aid in gathering the Australian data is acknowledged separately below. 
matter, given that reference (as opposed to denotation) seems properly to belong to pragmatics. However, there are equally clearly important links to grammar; and in the transformational tradition problems of anaphora have always had a certain prominence (recollect 'pronominalization', 'equi', etc.; see references in Farmer, I984: I6I ff.). Over the last five years, however, by a stroke of genius or perversity (according to your view) anaphora has come to take a crucial role at the heart of the Government-Binding theory of grammar. Whatever your view, this development portends an upsurge in work on the interface between grammar and pragmatics. Predictably, there are many who think that Chomsky has over-grammaticized what must by its nature intrinsically have a large pragmatic content, and Reinhart (1983), Farmer (1984), Farmer \& Harnish (1987), Kempson (1985) are representative of a recent trend to try to re-apportion the burden of account between grammar and pragmatics. It would be useful to appraise these different attempts, but that would be the subject of another paper. Here I will simply promote another, largely independent, approach that emerges naturally from work that Atlas, Horn and I have been doing on the Gricean maxims of Quantity.

In what follows I shall concentrate on NP-anaphora, and especially the opposition between zero-anaphora (i.e. non-trace NP-gaps) ${ }^{2}$ and pronominal anaphora. I shall try to make a case for the idea that there are general pragmatic principles that account for the favoured interpretations of certain NP-gaps, and that this potentially undermines the Chomskyan claim that NP-gaps are the key to the study of the specific cognitive faculty at the heart of linguistic competence (see quote at head). I must add that the pragmatic principles I shall adduce are just some of many that can be seen to operate in anaphora - and in the data we will be working with there are thus inevitably many places where my principles will not provide anything like the whole story.

\section{THE PROBLEM: ZERO-ANAPHORA AND A GENERAL ANAPHORA PATTERN}

\section{I.I. Zero-anaphora in Guugu Yimidhirr}

The pragmatic approach to anaphora, and in particular zero-anaphora, to be outlined below was suggested to me by exposure to an Australian language.

[2] Terminology is a problem here: I shall use ZERO-ANAPHORA as a general cover term over non-trace NP-gaps (or sometimes simply NP-GAP), in order to avoid theoretical commitment to PRO, pro, slash-categories, etc.; we then need another term for an NP-gap which does not belong to the family of grammatically controlled NP-gaps, where the NP can equally well (pragmatic effects ignored) be overt, as in English conjunction reduction. I suggest 'zero-anaphor proper'. Of course, there is no principled reason why the term zero-anaphora should not cover VP-deletion (gapping) and the like, but I do not discuss these problems in this paper. We also need a theory neutral term for NP-gaps that are not anaphoric in nature, e.g. for 'obviative PRO'. 
The language is Guugu Yimidhirr, spoken in Northern Queensland about 250 miles North of the Cairns area where Dyirbal and Yidiny, the languages well-known through Dixon's descriptions (1972, 1977), were spoken (Guugu Yimidhirr is structurally closer to Yidiny than to Dyirbal, but structurally distinct from both). My analysis will be based quite largely on the excellent description in Haviland (1979a), supplemented by my own data. ${ }^{3}$

Up to a point, anyway, we can talk of zero-anaphora as the use of gaps to pick up reference by linkage to antecedents, as in English conjunction-reduction,

\section{(1) John gave Mary a kiss and $\emptyset$ smiled}

without presuming any theoretical typology of such gaps. In English, NP-zero-anaphora is highly grammatically constrained, occurring more or less only in subject position (actually the range is somewhat increased if you look at utterances in discourse rather than sentences in the linguistic operating theatre, but I leave that aside).

Now, in Guugu Yimidhirr NP-zero-anaphora seems, with one or two possible exceptions, ${ }^{4}$ grammatically unconstrained: that means any NP whatsoever in any structural location can fail to have overt realization. To see what this does to discourse, consider the English gloss in (2) of a typical Guugu Yimidhirr text (given in Appendix I). (I shall use 'referential indices' here and throughout this paper to indicate the actual or preferred interpretation that is being discussed - they are not intended to have any special theoretical significance.)

(2)

I67 B: $T h e y_{1 / 2 / 3 / 4}$ looked at one another

I68 $\emptyset_{1 / 2 / 3 / 4}$ grabbed one another

$169 H e_{1}$ was you know -

$170 \quad$ That chap $_{1}$ he $e_{1}$ was really gigantic

I7I R: $\emptyset_{1}$ was really gigantic

$172 h e_{1}$ was Jimmy Lee's younger brother

[3] I am grateful to Department of Anthropology at the Research School of Pacific Studies of the Australian National University and to the Australian Institute for Aboriginal Studies for generous financial and logistic support. But without John Haviland's and Leslie Devereux's introductions to Tulo Gordon and his family, the late Jack Bambi, and Roger Hart, and many kinds of help from the community of Hopevale, the support would have been of little avail. Field work was done with Penelope Brown from June-October 1982, and was actually concentrated on a collaborative project distinct from that reported here. The debt to Haviland's grammatical and lexicographical work on Guugu Yimidhirr is considerably more fundamental than the copious references indicate; my reinterpretation of some of his findings are thus strictly tentative. This essay is dedicated to the memory of our late dhowuunh, a man of outstanding verbal and non-verbal resource; I only wish I could have learnt more from him.

[4] One exception, is the apparent constraint adduced by Haviland (1979a: 137) to the effect that objects of purposive clauses do not seem to be deletable under co-referentiality with the 'subject' of an intransitive matrix clause. 
I73 B: Yeah. $\emptyset_{1}$ grabbed one/another (e.g. 3)

$174 \quad \emptyset_{1}$ threw $\emptyset_{3}$

I75 R: $\emptyset_{1}$ threw another, eh?

I76 B: Then $\emptyset_{1}$ threw another (e.g. 4)

I $77 \quad$ Bulii-bulii $i_{2}$ was er -

$179 \mathrm{R}:\left(\emptyset_{2}\right.$ was $)$ helpless

180 B: $\quad\left(\emptyset_{2}\right.$ was $)$ helpless

$182 \emptyset_{1}$ took him $_{2}$ and

$183 \quad \emptyset_{1}$ threw him $_{2}$ too

184 while $\emptyset_{1}$ was hitting him that one ${ }_{3 / 4}$ ((points $\left.N\right)$ )

I85 $\mathrm{He}_{2}$ this chap ${ }_{2}$ to the South recovered ((points $\left.\mathrm{S}\right)$ )

I87 R: $\emptyset_{2}$ got up?

$188 \mathrm{~B}: \emptyset_{2}$ got up and $\emptyset_{2}$ grabbed a gun

I89 $\emptyset_{2}$ shot $\emptyset_{2}$ with the gun

I90 R: Wow!

I9I B: Bang! The end!

192 R: $\emptyset_{1}$ was finished

I93 B: $\oint_{2 / 3 / 4}$ stood around

Bulii-bulii, ${ }_{2}$ took a rock

I94 R: $\emptyset_{2}$ crushed $\emptyset_{1}$ 's chest (with the rock)

195 B: ((bangs chest))

197 B: $\emptyset_{2 / 3 / 4}$ lifted $\emptyset_{1}$

$198 \emptyset_{2 / 3 / 4}$ carried $\emptyset_{1}$ away to the West

This example should make the dimensions of the problem clear: how do native speakers track referents given the apparently random deletion of NPs in different grammatical relations? Notice that the following kinds of simple rule would fail:

(a) 'zero subjects are co-indexed with preceding subjects' (A or S NPs) ${ }^{5}$ : counter-examples in lines $180 / 182 ; 194 / 197$,

(b) 'zero NPs are co-indexed with preceding NPs in same underlying case' (i.e. the operative concepts may be ergative/absolutive, not subject). E.g. an O-NP (object NP) in absolutive case will act as antecedent for a zero S-NP

[5] Throughout this paper I shall use Dixon's (1980: 286) unambiguous labels for core NP grammatical functions: A (for agent) labels the 'subject' of a transitive verb, $O$ (for object) the other core NP in a transitive sentence, $S$ (for 'subject') the single core NP of an intransitive sentence. Thus absolutive case will mark $\mathrm{O}$ - and S-NPs, nominative case $\mathrm{S}$ - and A-NPs, etc.

Guugu Yimidhirr examples are given in the practical orthography used in Haviland's (1979a) description and more or less standard in recent descriptions of Australian languages.

When glossing Guugu Yimidhirr I have used the abbreviations approximately as in Haviland, (1979a): (a) Case inflections: NOM (Nominative), ACC (Accusative), ERG (Ergative), ABS (Absolutive), DAT (Dative), LOC (Locative), ADESS (Adessive), COMIT (Comitative), PRIV (Privative); (b) Verbal inflections: ANTIP or REFL (Reflexive/Anti- 
which would be in absolutive case if it was overt. Case in point: $\emptyset_{1}$ in line I 89 is an O-NP, $\emptyset_{1}$ in 192 is an S-NP. However, a counter-example to that rule is provided by the prior clause: ' $\varphi_{2}$ (S-function) got up and $\emptyset_{2}$ (A-function) grabbed a gun' - the first $\emptyset_{2}$ would be in absolutive case if overt, the second in ergative case.

Talk in terms of 'givenness', etc., will clearly not help: not all zeros (NP-gaps) are necessarily 'given' (are anaphoric or have definite reference, see below), and of those that ARE anaphoric (as in the text) notions of topic, or theme (as opposed to rheme), or givenness, etc., will hardly help to distinguish and co-index the relevant gaps. In fact, the matter turns out to be complex and involve things as diverse as Guugu Yimidhirr conceptions of space, gestural channels of communication, the kind of shared knowledge only presumable in a closed social world of 600 individuals, and aspects of conversation structure. Nevertheless, an important ingredient in the solution is, I shall claim, some quite general pragmatic principles, and it is these that I want to examine further.

\section{I.2. The pattern to be accounted for}

Conceding that there is no single solution to the Guugu Yimidhirr problem of NP-gap interpretation, the particular pattern that I am interested in giving an account of is the following. Consider an English sentence like:

(3) John 1 came into the room. $\mathrm{He}_{1}$ sat down. The $\operatorname{man}_{2}$ coughed.

My claim is that the preferred interpretation is as indicated by the indices: i.e. the reduced pronominal form tends to pick up reference from the last relevant NP (preferably a subject). Reversion to a full lexical NP (The man) tends to implicate disjoint reference. Since these are merely default implicatures, operative in the absence of information to the contrary, it will of course be possible to find many exceptions to these tendencies - but in these cases there should be specific reasons to prefer another interpretation.

Now consider the Guugu Yimidhirr sentence:

(4) John nyulu gaday. $\emptyset$ minha buday. John-ABS ${ }_{1}$ he-NOM ${ }_{1}$ came. $\emptyset_{1}$ meat-ABS ate. 'John ${ }_{1}$ came. $(\mathrm{He})_{1}$ at meat.

$\begin{array}{lll}\text { dyiirraanh } & \text { nyulu } & \text { dhaday. } \\ \text { man- } \mathrm{ABS}_{2} & \text { he-NOM} & \\ \end{array}$ The $\operatorname{man}_{2}$ left'

passive), PAST, NON-PAST, PURP (Purposive), REDUP (reduplicated stem, indicating aspect); (c) Number on nominals: PL (plural); Dual (dual); (singular is unmarked); (d) Pronouns: sometimes just given nearest English equivalents, or glossed by the customary Is, 2s, Ipl, etc. (all Guugu Yimidhirr pronouns are unmarked for gender and presuppose animacy). I have not given consistent morpheme segmentation where this was irrelevant to the point at issue and might be distracting; zero morphs are only sometimes glossed; the reader is referred to Haviland, (1979a) for a thorough description of the morphology. 
(As I will explain in a moment, animate lexical NPs are usually accompanied by a redundant pronoun.) Here the pattern is: zeros (NP-gaps) pick up reference from prior relevant NPs. Reversion to a full lexical NP (typically plus pronoun), and even to an overt pronoun, will tend to implicate disjoint reference. Both these examples are constructed for expositional reasons; naturally occurring examples from English and Guugu Yimidhirr appear in Appendices 2 and 3 respectively.

The generalization across the two patterns I want to make is this: the more 'minimal' the form, the stronger the preference for a co-referential reading. ${ }^{6}$ I will explain what I mean by minimal below, but for now we can simply set up a scale:

\section{(5) Lexical NP $>$ Pronoun $>\emptyset$}

such that moving to the right favours a co-referential reading, while a reversion to the left implicates a disjoint reading. And the pattern is in fact unified across the two languages since Guugu Yimidhirr often moves step by step from full lexical NP reference on first mention, to pronoun to zero; while in English we can also move to zero anaphora in conjunction reduction and subjectless infinitive clauses:

(6) John came in and $\emptyset$ sat down. The man coughed.

In this case the pattern crosses over the pragmatics/semantics borderline: this sentence does not merely implicate that John sat down, it entails that John sat down. In fact, I submit that this is part of the interest of the pattern - it is such a prevalent pattern of interpretation that it tends to get grammaticalized and semanticized.

\section{INTERLUDE: GUUGU YIMIDHIRR GRAMMAR AND ANAPHORA}

To understand the Guugu Yimidhirr problem we clearly need to understand a bit more about the grammar. Obviously, here I can only sketch the aspects pertinent to our theme (but see Haviland, I979a).

\section{I. Guugu Yimidhirr in the typology of reference-tracking systems}

A useful beginning is to place Guugu Yimidhirr within the Foley \& Van-Valin (1983: Ch. 7) typology of reference-tracking systems. 'Reference tracking' is a problem that arises only because of the preference for abbreviated forms of nominal reference - a preference that is explained by pragmatic principles introduced below; given abbreviated and semantically general forms (pronouns, NP-gaps) the problem of making the correct anaphoric links between nominals arises. Foley \& Van Valin suggest there are four basic solutions to

[6] This observation is no doubt far from novel. Compare the independent observations in Haiman, 1985: $172 \mathrm{ff}$. 
this problem: (a) switch-reference systems (marking of change of protagonist), (b) switch-function systems (e.g. subject prominence plus subjectpromotion rules like passive), (c) gender systems (i.e. cross-reference of NPs by verb agreement), ${ }^{2}$ and (d) pragmatic systems, as in Chinese and Guugu Yimidhirr, where there is no grammatical solution at all. Guugu Yimidhirr falls into the last category for the following reasons: (i) it has no switchreference system; (ii) it lacks the kind of switch-function system exhibited by nearby Dyirbal, which has absolutive 'pivots' and an 'antipassive' in the strict sense; (iii) it lacks any kind of agreement whatsoever between the verb and its valents. Further, pronouns encode only number (singular/dual-plural in the 3 rd person) not gender (though they are only properly used of animate or animated entities like boats, the moon, etc.). In short, Guugu Yimidhirr has no grammatical back-up system to guarantee anaphoric link-ups, let alone recoverability of missing NPs. These are features its shares with a number of languages that have very widespread zero-anaphora, including Chinese, Korean and Malayalam, indicating that the idea (Chomsky, 1982: 86) that the pro-drop parameter (assuming that this is the relevant parameter, as in Bouchard, 1983: 157) is correlated with 'rich' inflectional systems is mistaken (see also Mohanan, 1983: 665).

\subsection{Further basic facts about Guugu Yimidhirr grammar}

Let me provide immediately some further properties of Guugu Yimidhirr grammar. Guugu Yimidhirr is a morphologically ergative language, with typical split ergativity so that lexical NPs and demonstrative and interrogative pronouns get ergative/absolutive case, while other pronouns have nominative/accusative case inflection (see Dixon, 1979). Therefore, we must be cautious about talking of 'subjects' and 'objects' and, following the Australianist tradition, we shall talk about NPs in A function (agents of transitive verbs), O-function (objects of transitive verbs), and S-function (the single NPs of intransitive verbs). However, where we need cover terms for NPs in $A$ and $S$ functions, or NPs in S- and O-functions, we can use the terms 'subjects' and 'absolutive NP', respectively.

In current MIT language typology, Guugu Yimidhirr is a classic nonconfigurational language (i.e. there is no clear way in which one could define grammatical functions like A, S or O configurationally) (Chomsky, 198I: $127 \mathrm{ff}.)^{8}$ It is also a $\mathrm{W}^{*}$ language (in fact a rather better example than Warlpiri, the original prototype): i.e. a language where there is little

[7] Incidentally, the typology mistakenly, in my opinion, conflates honorific tracking systems with gender systems; gender systems cross-reference NPs with intrinsic gender-class, honorific systems cross-reference NPs with honorific-category relative to the speaker's social status - in short honorific classes are deictic categories while gender classes are invariant to deictic parameters.

[8] See Heath (1986) for a discussion of how the concept of non-configurationality applies to Australian languages. 
independent motivation for constituency. $\mathrm{W}^{*}$ languages are characterized by (a) very free word order, (b) great freedom in the way valents are realized - e.g. a valent in A function may be realized as a discontinuous string of half a dozen nominals, or nothing at all (a zero NP). ${ }^{9}$ The main constraints are imposed by verb valency or subcategorization, which imposes a limited set of nuclear cases of determinate type, so that each nominal must receive one of these kinds of case-marking if it is to be interpreted as a nuclear verb valent (although it may receive non-nuclear cases and be interpreted as an adjunct). In Guugu Yimidhirr, as far as I can determine, there appear to be just two possible kinds of evidence for constituency: (a) where two or more nominals are in a head-modifier semantic relation, and would normally be identically case-marked, the case-marking may be omitted from the modifying nominal just in case it immediately precedes the head (or is only separated by another such modifier; see Haviland, 1979a: 56-57); (b) subordinate clauses are normally not scrambled with matrix clauses, but precede or (mostly) follow them. Even these constraints though admit of exceptions: thus the uncase-marked head may perhaps immediately follow a genitive modifier (if only exceptionally), ${ }^{10}$ and there are not only interclause movements of a possibly rule-governed sort - in the form of infinite verb preposing (Haviland, 1979a: 136) or subordinate A-NP 'hopping' (ibid. I 54) - but also of a more unconstrained kind." ${ }^{11}$ This lack of ordering facts makes a dependency analysis, as in either relational grammar or word grammar (Hudson, 1984), the natural description technique (Blake, 1983; but for the treatment of free order in constituency terms see Gazdar, Klein \& Pullum, I983).

\subsection{Guugu Yimidhirr under a GB account}

At this point, in trying to understand the distribution of NP gaps it will be useful to review Guugu Yimidhirr structures under the categories of a GB

[9] Hale (1983) gives a sketch of $W^{*}$ properties; Farmer (1984: I I ff.) describes a related 'category-neutral' phrase structure in more detail.

[10] For example, one finds in texts not only:

biiba yarrga-aga-mu-n

father boy-GEN-mu-ERG 'The boy's father' (ergative NP)

where biiba carries no case inflection, but also

yarrga-aga-mun biiba

boy-GEN-mu-ERG father 'The boy's father' (ergative NP).

Haviland, however (personal communication), considers this last form to be clearly ungrammatical. If he's right, then this pattern constitutes the only exceptionless evidence for constituency, which establishes only the unit NP.

[i1] Here is an example, drawn from a text kindly provided by Haviland, where the item in italics has leapt from a purposive subordinate clause into the matrix:

ngayu nhanu milga-ngandaadhi [nhagala miirriinhu]

I-NOM you-ACC forgot that-ABS show-PURP

'I forgot [to show you that]' 
account. This has some perversity, since if any language resists such a treatment, Guugu Yimidhirr does. Without constituency we can hardly define the essential configurational notions like c-command, minimal governing category, etc., presupposed by the GB account. However, putting the problem in GB terms is quite illuminating if only because it serves to emphasize the differences between English and Guugu Yimidhirr.

2.3. I. Binding. Let us take the binding conditions one by one (I shall use the three conditions of Chomsky's (1981) formulation not the 1982 twocondition system; and I use the terminology in Radford (198I: 367), and Koster \& May (1982: 137), to avoid the term R-expression as we are not concerned with Wh-traces): ${ }^{12}$

(7) Binding Conditions

A. Anaphors must be bound in their governing category

B. Pronouns must be free in their governing category

C. A lexical NP must be free everywhere.

(The term 'anaphor' is here, of course, used in the special GB sense of a reflexive or reciprocal expression; and not in the sense intended in 'zeroanaphor', etc.)

Condition A: Anaphors are bound in their governing category

The English reflexive and reciprocal pattern is of course as in:

(8) (a) They hit themselves

(b) They hit each other

Looking for the Guugu Yimidhirr equivalent, we encounter our first problem: Guugu Yimidhirr has no reflexive or reciprocal pronouns or morphemes. To translate English reflexives or reciprocals one uses what in Australian languages is usually called the anti-passive, i.e. the equivalent in an ergative language to the passive in a nominative/accusative language. Now in Guugu Yimidhirr the 'antipassive' (expressed as a verb inflection) is pretty multifunctional (as in Yidiny; Dixon, 1977: $273 \mathrm{ff}$ ): it just takes a transitive verb and knocks off a valent, leaving an intransitive verb with a (possibly null)

[12] Nigel Vincent points out to me that the category R-expression might unify the class of NPs that take ergative/absolutive inflection in Guugu Yimidhirr; for interrogative pronouns, unlike most other pronouns which inflect on a nominative/accusative pattern, are case-marked like full lexical NPs. However, the exact placing of the split between ergative/absolutive and nominative/accusative case marking in Australian languages is very variable (Dixon, 1979), so we can attach no great importance to it here. Indeed, there are in Guugu Yimidhirr non-interrogative pronominals, like nhaa- 'that one, those', that exceptionally take ergative/absolutive case-marking (nhaamuun, nha(a)yun) and the interrogative pronouns also have non-interrogative indefinite uses (Haviland, 1979a: 69-72). 
NP in S-function. ${ }^{13}$ This is open to various semantic interpretations in the most rational way: indefinite or accidental agency, reciprocal actions by a plural S-function NP, or reflexive action by an agent upon itself. So:

(9) bama

gudhiirra gunda-dhi

people-ABS two-ABS hit-ANTIP

could mean 'the two people each hit themselves', 'the two people hit one another' or even 'someone (unidentified) hit the two of them (accidentally)'. In fact, this construction can perform both antipassive functions (making an A-NP into an S-NP) and passive functions (making an O-NP into an S-NP), the distinction being clear when the S-NP is a pronoun (the 'antipassive' pronoun will be nominative, the 'passive' pronoun will be accusative; see Haviland, I979a: 123 f.). ${ }^{14}$

Notice that apart from the broad functions of the construction (roughly, a warning of one missing NP), when construed as a reflexive construction the fact that the surviving NP in S-function need not be overt means that the 'binder' of the 'anaphor' is not always available (it may be outside the clause or minimal governing category or it may be 'exophorically' given), while the 'bindee' (or 'anaphor') is subsumed within the verb-morphology: the facts clearly do not fit the GB framework. Nevertheless, Haviland (1979a: I2I) claims that the reflexive/reciprocal function is central, and in this he is undoubtedly correct, so let us henceforth call this the 'reflexive' construction. ${ }^{15}$

[13] Dixon, (1977: 412) cites Langacker \& Munro's (1975) claim that the conflation between reflexive and passive/antipassive is in fact typologically common. (See also Lichtenberk, 1985; Haiman, 1985: 143.) Dixon claims that in the reflexive use one could hardly distinguish between antipassive and passive -i.e. between O-NP and A-NP origins for the lone S-NP; but the Guugu Yimidhirr pronominal evidence (see following footnote) seems to favour an A-NP origin for the S-NP in the antipassive construction in its reflexive uses. The notion 'antipassive', due to Silverstein, is discussed in Dixon, 1977: 277 ff., but in essence relates in a transformational way a sentence of the form ' $A_{1}$ V-trans $O$ ' to ' $S$, V-intrans' (for example, in gross English gloss, 'John hit someone' to 'John did-a-hitting').

[14] Haviland discusses the following kinds of sentence:

(i) ngayu wagi-idhi

I-NOM cut-ANTIP

'I cut myself'

(ii) nganhi wagi-idhi

me-ACC cut-ANTIP

'I got cut accidentally'

These have considerable theoretical interest. First, they indicate that Guugu Yimidhirr 'antipassive'// reflexive' is an exception to the cross-linguistic generalization that 'passive absorbs Case' (Chomsky, 1981: 129). Second, the dual nature of the Guugu Yimidhirr antipassive/passive indicates that a Relational Grammar hierarchy could not be set up across NP functions: for, if the hierarchy is $A>S>0$, then while an O-NP can be 'promoted' to S, an A-NP can equally be 'demoted' to S.

[15] Incidentally, the reflexive/reciprocal interpretation of the construction can be reinforced by the addition of the emphatic suffix -:gu to the S-NP if it is overt. There is a notable cross-linguistic tendency to associate reflexives and emphatics (cf. English He himself wrote 
A point to highlight is that the Guugu Yimidhirr 'reflexive' does not have the same range of application as English reflexives: viewing the Guugu Yimidhirr reflexive as a transformation, it operates on underlying A-NPs or O-NPs to make them into S-NPs. But there is almost no possibility, as there is in English, of an oblique NP (as in a prepositional phrase like to himself, etc.) being 'reflexivized'. ${ }^{16}$ The theory below makes considerable hay out of the complementary distribution of reflexives and non-reflexive pronouns wherever the latter are interpreted as coreferential with another (c-commanding) NP in the clause. This will predict a difference in the preferred interpretations of oblique NPs in English and Guugu Yimidhirr: where these are pronominal (but a reflexive could have occurred), in English we will prefer an interpretation disjoint with a c-commanding NP (as in John gave the book about him to Mary) but in Guugu Yimidhirr there should be no such preference.

We turn now to the second binding condition.

\section{Condition B: Pronouns are free in their governing category}

Corresponding to English:

(Io) John hit him $_{2}$

we have the Guugu Yimidhirr:

$\begin{array}{ll}\text { John-ngun nhangu } & \text { gund-ay } \\ \text { John-ERG him-ACC } & \text { hit-PAST } \\ \text { 'John, hit him,' } & \end{array}$

$i t$, the similar uses of Tamil taan, etc.). The explanation for this is perhaps partially given by the pragmatic principle introduced below as the $\mathrm{Q} / \mathrm{M}$-principle, which will predict that 'reinforced' NPs will be given a contrasting interpretation.

[16] Haviland points out to me that this is an oversimplification: a few verbs allow reflexivization of such oblique NPs on a reciprocal interpretation. Compare for example the following:

(i) nyulu nhangu Bob-wi galga wuu-dhi he-NOM he-DAT Bob-DAT spear-ABS give-PAST 'He gave the spear to Bob'

(ii) bula galga-wi wuu-dha-adhi 3dual-NOM spear-DAT give-FORM-REFL+PAST

'The two gave spears to each other'

Note in (ii) the 'antipassive' demotion of the object ('spears') to oblique case - see discussion in Haviland, (1979a: 128-129). One area, incidentally, where Guugu Yimidhirr permits reflexivization but English does not is with an agent's actions on his own (inalienably possessed) body parts - 'I hit my own foot' must thus be expressed as:

ngayu dhamal gunda-adhi

I-NOM foot-ABS hit-REFL + PAST

'I hit myself on the foot'.

But the point is that there should be, on the hypothesis to be developed below, a systematic interpretation of non-reflexive forms determined by the possibility or non-possibility of reflexivizing the NPs in those locations in any particular language. 
Now there is something right about Condition B for Guugu Yimidhirr also: pronouns, and gaps too, will not be interpreted as coreferential with a pronoun or lexical NP acting as a nuclear valent within a clause (with an essential proviso I shall make in a moment), for the reflexive/antipassive is the right way to express such coreferentiality. Further, there is a parallel to English where both S and NP are the relevant 'minimal governing categories' (MGCs):

(I2) John 1 asked [his I/2 $_{\text {father] }}$

(13) John-ngun [biiba nhangu-:gu] John-ERG [father-ABS he-GEN-ABS-EMPH] asked

'John asked his $_{1 / 2}$ father'

His and the corresponding Guugu Yimidhirr pronoun nhangu only have to be free (it seems) within their NP (marked with square brackets); thus they can be (optionally) coreferential with the 'c-commanding' John outside the NP. ${ }^{17}$ A difficulty here is that NP in Guugu Yimidhirr is not clearly a constituent given the virtually free word order; and notions like c-command are here totally metaphorical since there is no constituent structure over which they can be defined: (they might of course be held to hold at the level of LF, but I take that too to be a fairly metaphorical idea).

But the main proviso we have to make is that the Guugu Yimidhirr sentences just illustrated are not the preferred form - instead they would normally have an apparently redundant pronoun coindexed with the lexical NP:

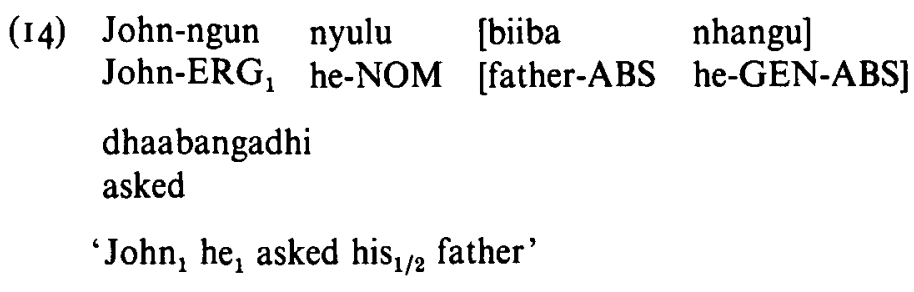

In these circumstances, pronouns are acting like quasi-classifiers - recollect that pronouns can only be used to refer to animate entities; and Guugu Yimidhirr uses generic nouns as classifiers in a similar way yielding redundant NPs glossing as 'food flour', 'meat beef', etc. (see Dixon, 1982: Ch. 6 on

[17] The emphatic suffix -:gu in (13) strongly favours the co-referential reading, just as it favours the reflexive interpretation of the anti-passive/reflexive verbal inflection (see footnote 15). However, without it both the co-referential and disjoint readings are equally possible. The way in which such a 'pragmatic' particle can shift the balance between the readings is some general indication of the importance of pragmatic factors in the determination of co-reference in Guugu Yimidhirr. 
the similar classifiers in Yidiny). ${ }^{18}$ But the relevance is that such pleonastic pronouns of course break the binding condition B: they are coreferential with a c-commanding NP in their minimal governing category (here, NP). The generalization to make of course is that we need to add a further condition: pronouns in Guugu Yimidhirr may not be found within their minimal governing categories (MGCs) UNLESS THEY HAVE THE SAME THETA-ROLE (or $\mathrm{A}, \mathrm{S}, \mathrm{O}$ or possibly peripheral function) as a lexical $\mathrm{NP}$, in which case they can, indeed must, be co-indexed. ${ }^{19}$ (Note that, given the split ergativity, we cannot state the extra condition in terms of identical case-assignment.)

We come finally to the third binding condition.

\section{Condition C: Lexical NPs must be free everywhere}

In English, we cannot normally construe a lexical NP c-commanded by a pronoun as coreferential with the pronoun:

$$
\begin{aligned}
& \text { *He hit John's father = bad since 'he' c-commands 'John' } \\
& \mathrm{John}_{1} \text { hit his }{ }_{1} \text { father }=\text { OK since 'John' c-commands 'his' }
\end{aligned}
$$

Here we have already noted one way in which Guugu Yimidhirr fails to parallel English: since pleonastic pronouns (as in John nyulu) are co-indexed with NPs, animate lexical NPs in Guugu Yimidhirr are not normally free. However, we can make an exception of such pronouns with identical Theta-role. But there are still marked differences with English: co-referential lexical NPs freely occur in sentences with more than one clause; compare English and Guugu Yimidhirr in the following:

[18] There is a lot of evidence that pronouns in Australian languages are very different in nature from English pronouns, being more 'nominal' and less 'pronominal': (a) many Australian languages lack 3rd person pronouns; (Dixon, 1979: 357); (b) in Guugu Yimidhirr pronouns can take adjectives as modifiers (Haviland, I979a: 103); (c) the 'classifier' function in Guugu Yimidhirr also serves the purpose of disambiguating between $\mathrm{O}$ - and S-NPs in absolutive case, since O-NPs will take accusative pronouns, S-NPs nominative pronouns (Haviland, 1979b; Dixon, 1977: 274); (d) zero-anaphors absorb many of the functions of English pronouns.

[19] 'Must' is a little strong - it is quite normal to say:

$\begin{array}{lll}\text { John } & \text { bula } & \text { gad-ay } \\ \text { John-ABS } & \text { they-dual-NOM } & \text { come-PAST }\end{array}$

meaning 'John and the other guy came'. The condition seems to be that there is at least partial referential overlap. This has been noted as a general problem for the Binding Conditions in English too; see, e.g. Higginbotham, (1983). A further problem for this emended version of Binding Condition $B$ is that the solution may then violate the "Theta criterion', namely 'each Theta-role is assigned to one and only one argument' (Chomsky, 1981: 36); for the agentive Theta-role, or indeed grammatical S-function, in the above sentence is assigned to two nominals of distinct reference. Much would clearly depend here on the definition of 'argument'. Nigel Vincent suggests to me that a natural GB solution to the problem of pleonastic pronouns is to assimilate them to pronominal clitics and thus to agreement phenomena; but the problem of overlapping reference would seem to be an impediment to that solution. 
(16) (a) *John's father told him ${ }_{1}$ [that John, should make it]

(b) John-ga-m-un biiba-ngun nhangu gurray

John-GEN-m-ERGfather-ERG he-ACC told

'John's, father told him 1

[John-ngun nyulu nhayuun balga-nhu]
John-ERG he-NOM that-ABS make-PURP
[that John he $_{1}$ should make it]'

In the English sentence co-referentiality as marked is ruled out since (it may be argued) him c-commands the lexical NP John in the subordinate clause. But the corresponding Guugu Yimidhirr sentence is apparently fine, if contrastive in emphasis. The contrastive force is no doubt related to the preference for a zero-NP instead of the second lexical NP in structures of this sort, but the repetition is grammatical enough. Thus although Condition $\mathrm{C}$ cannot be held to hold at a grammatical level, it does in fact quite well describe a usage preference.

2.3.2. Control in Guugu Yimidhirr. In the same wayward spirit, let us go on to ask whether there is anything that might correspond to the Theory of Control, as constructed to handle NP gaps in English subjectless infinitive clauses in particular. (We may adopt a relatively theory-neutral definition of control like the following: 'a controlled clause is a clause, one of whose arguments is obligatorily left unexpressed under identity with an argument in another clause' (Simpson \& Bresnan, 1983: 59; cf. Gazdar, Klein, Pullum \& Sag, 1985: 200).) In the case of Guugu Yimidhirr this amounts to asking whether some of the many zero anaphors have grammatically specified antecedents, and whether these particular zero anaphors are found in locations that are ungoverned.

To deal with the last issue first, the closest approximation to a subordinate infinite clause in Guugu Yimidhirr is the purposive clause, which would normally translate, inter alia, 'in order to' clauses in English. ${ }^{20}$ In such clauses the tense marker is replaced by the suffix -nhu. Compare the following Guugu Yimidhirr sentence and its English gloss (from Haviland, 1979a: 137):
(I7)

nganhi $_{1}$ dhana dubi
me-ACC they-NOM left-PAST
'They left me [PRO to die]'
$\left[\emptyset_{1} \quad\right.$ biini-nhu $]$
(me) die-PURP
'They left me [PRO to die]'

However, the parallel is awkward for four reasons. First, in English, infinitives are said to have overt subjects just in two marked cases: (a) with

[20] As in many Australian languages (Dixon, 1980: 310 ), there is a precise parallel between purposive NPs and purposive clauses (Haviland, 1979a:135) so there might be an argument that purposive clauses are in fact peripheral or adjunct NPs. However, that should not be taken to imply true subordination: by Dixon's criteria, generalized from work by Hale, Guugu Yimidhirr purposive clauses must be seen as 'adjoined' and not 'embedded ' (Dixon, 1977: $423 \mathrm{ff}$ ). Nevertheless, for convenience, I shall continue to use the terms 'subordinate' and 'matrix' clause in order to set up the parallels and differences between English and Guugu Yimidhirr. 
'raising' verbs (S-bar deletion), and (b) preposition taking verbs like 'want (for)'. These are held to be principled exceptions to the generalization that infinitives have ungoverned subjects, obligatorily filled by the phonetically null element PRO. However, in Guugu Yimidhirr purposive clauses overt NPs in A- or S-function can freely appear; thus compare the English and Guugu Yimidhirr sentences below (see also (20b)):

(I8) (a) [John's father] asked him ${ }_{1}\left[\mathrm{PRO}_{1}\right.$ to make it]

(b) [John-ga-m-un biiba-ngun] nhangu dhaabangadhi John-GEN-m-ERG father-ERG he-ACC asked '[John's ${ }_{1}$ father] asked him ${ }_{1}$

$\begin{array}{ccc}\text { [nyulu John-ngun } & \text { balga-nhu] } \\ \text { he-NOM John-ERG } & \text { make-PURP } \\ \text { [he } \text { John }_{1} \text { to make (it)] } & \end{array}$

Secondly, when they appear, they appear case-marked, and therefore are clearly governed. Thirdly, since NP-gaps occur freely in Guugu Yimidhirr in all positions (barring one exception to be discussed below), there is no particular reason to think that NP-gaps in purposive clauses are a specific type of zero anaphor. (We shall be concerned in 2.3.3 below with the question of the possible identification of NP-gaps in Guugu Yimidhirr purposive clauses with PRO or pro, etc; here we are concerned rather with the question whether there is any distinction at all between zero anaphora in Guugu Yimidhirr main clauses and 'controlled zeros' in Guugu Yimidhirr purposive clauses.) Finally, a fourth problem is that the purposive clause may appear alone as a matrix clause expressing intended action or desire (Haviland, 1979a: 92), and there are many indications of an 'adjoined' rather than 'embedded' status (see footnote 20 above). ${ }^{21}$

Nevertheless, there are some ways in which zero-anaphors in Guugu Yimidhirr purposive clauses behave in a fashion parallel to PRO in English infinitives. For example, we can see the analogues of the distinction between subject- and object-controlling predicates:

(I9) Subject control

English: $\mathrm{John}_{1}$ promised $\left[\mathrm{PRO}_{1}\right.$ to go]

GY: John-ngun ${ }_{1}$ nyulu milbi John-ERG he-NOM promised go-PURP 'John promised to go'

Notice that the matrix NP in A-function and ergative inflection (John) is here the antecedent for the gap in S-function (which if filled by an overt NP would appear in absolutive inflection); so here, as elsewhere in Guugu Yimidhirr syntax, there is no indication of syntactic ergativity, and we can talk felici-

[21] In fact, nearly all 'subordinate' verbal inflections in Guugu Yimidhirr can also occur in independent main clauses, reinforcing the impression that there is no real subordination in Guugu Yimidhirr. 
tously of 'subject-control'. In most, if not all, such structures the gap can be optionally realized as an overt NP, at least in the form of a pronoun -i.e. 'deletion' does not appear to be obligatory, though it is certainly preferred. Thus, both (20a) and (20b) are grammatical on the indicated indexings.
(a) ngayu ${ }_{1}$ wawu-dhirr $\left[\varphi_{1}\right.$ mayi buda-nhu $]$ I-NOM soul-COMIT food-ABS eat-PURP 'I want to eat'
(b) nyulu ${ }_{1}$ wawu-dhirr [nyulu-gu ${ }_{1}$ buda-nhu] He-NOM soul-COMIT he-NOM-EMPH eat-PURP ' $\mathrm{He}_{1}$ wants [he $\mathrm{H}_{1}$ to eat]'

Where the subject of the purposive clause is 'deleted' (as in (20a)), there is a strong tendency to a coreferential interpretation. Particular matrix or 'control' predicates may differ in this regard: for example, the nominal predicate wawu-dhirr seems to exert relatively strict subject-control on a subordinate zero-subject, but exceptions can be found, as in (2 I a) (from a text, Bgest 92). ${ }^{22}$ If the subject of the subordinate clause is overt, it can be freely non-co-referential (as in (2 I b)) just as in English.
(a) nyulu $_{1}$ wawudhirr he-NOM soul-COMIT
$\left[\emptyset_{2}\right.$ yarrba dyaambi-nhu] 'He wanted [(it, the boat) to float that way]'
(b) ngayu wawu-dhirr [nyundu mayi buda-nhu] I-NOM soul-COMIT you-NOM food-ABS eat-PURP 'I want [you to eat food]'

Other possible subject-controlling predicates are illustrated below ((23) from Haviland, I979a):

(22) Engl: I know [how PRO to make spears]
GY: ngayu binaal-:gu
[Ø galga balga-nhu]
I-NOM know-EMPH spear-ABS make-PURP
' $I_{1}$ know how $\left[\varphi_{1}\right.$ to make spears]'
(23) Engl: I am going hunting [PRO to dig yams]
GY: ngayu wadhin dhadaa [ $\emptyset$ gaangga baga-nhu] I-NOM hunt go-PRES yams-ABS dig-PURP ' $I_{1}$ am going hunting $\left[\emptyset_{1}\right.$ to dig yams]'

Turning now to object control predicates, we find that, as in English, directive verbs ('tell', 'ask', 'order', etc.) are object-controllers in Guugu Yimidhirr:

[22] So the pattern of subject-control seems less grammaticalized than in English want constructions. Nevertheless, Guugu Yimidhirr 'want' constructions (for which see Haviland, 1979a: I 16, 135, Dixon, 1977: 298) appear to be amongst the very clearest examples of grammaticalized subject-controlling structures in the language; however, I shall argue below that this is as much a matter of verb semantics as of syntax. 
(24) Object Control
(a) John-ga-m-un-
biibangun $\left\{\begin{array}{l}\text { gurray } \\ \text { dhaabangadhi }\end{array}\right.$
John
John-GEN-m-ERG father-ERG said/asked
John-ABS-
[nhayuun balganhu]
that-ABS make-PURP
' John ${ }_{1}$ 's father told/asked $\mathrm{John}_{1}\left[\emptyset_{1}\right.$ to make it]'
(b) nganhi dhaawi buliman-da
me-ACC summoned policeman-ERG
[ngayu dagu-ngay maani-nhul]
I-NOM things-PL take-PURP
'The policeman told me [I to get my things]'

Typically, as in English, the subject of the subordinate verb is null and coreferential with the object of the matrix clause, as in (24a). However, unlike English, the subordinate subject may be overt as in (24b) (see also ( 18 ) above). Further differences with English emerge: first, not only may the controlled NP be realized as a gap, so also may the controlling NP (the matrix object) as in (25).
(25) Muuni nyulu gurray $\emptyset$ [ $\emptyset$ gaari milgamul madhi-nhu] Muuni he-NOM told $\emptyset_{1}\left[\emptyset_{1}\right.$ NEG ear-PRIV V'IZER-PURP $]$ 'Muni told (them) [to not be disobedient]'

More striking still is that the gap in the purposive clause may be interpreted as non-coreferential with the matrix object. Consider the following (slightly abbreviated) text (from Haviland's text T84/Ib. nec: 17I):
'Tell King Nicholas ${ }_{1}\left[\emptyset_{1}\right.$ to go South to Laura]'

$$
\begin{aligned}
& \text { nhangu gaari miirriil-a nhangu nhayun } \\
& \text { he-ACC } \mathrm{ACC}_{1} \text { NEG tell-IMP }\left[\emptyset_{2} \text { he-ACC } \mathrm{AC}_{1}\right. \text { that-ABS } \\
& \text { diiga-nhu bada } \\
& \text { send-PURP down] }
\end{aligned}
$$

Here the first clause has an object-control predicate with the matrix object controlling the null subordinate subject, as might be expected; but the second clause has another normally object-controlling predicate (miirriil) which in this case fails to exert control over the subject-gap in the subordinate clause. In other contexts this clause might be interpreted as 'Don't tell him ${ }_{1}\left[\left(\mathrm{he}_{1}\right)\right.$ 
to take him $_{2}$ down South]'; but here, it is contextually clear, the intended

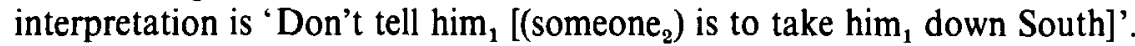

2.3.3. NP-gaps in Guugu Yimidhirr and the GB typology of empty categories. As mentioned, virtually any NP in Guugu Yimidhirr can be omitted. ${ }^{23}$ It is usual when talking of ellipsis to add the rider 'where the elided elements can be supplied from the context', but sometimes in Guugu Yimidhirr the missing element is taken - by virtue of its absence - to be indefinite and unspecified (Haviland, I979a: I 24; see, e.g. second clause of (26) above), a fact that will be important below. Now in the GB framework it is assumed that there is an interesting typology of NP-gaps, or empty categories, where the types are partially parallel to the three overt categories of NPs distinguished by the Binding Conditions (i.e. 'anaphors', pronominals and lexical NPs or Rexpressions). Or in feature terms (Chomsky, 1982: 78):

$\begin{array}{ll}\text { NP-trace } & \text { [+ anaphor, } \text { pronominal }] \\ \text { pro: } & {[\text {-anaphor, +pronominal }]} \\ \text { PRO: } & \text { [+ anaphor, +pronominal] } \\ \text { Wh-trace or variable: } & \text { [- anaphor, - pronominal]. }\end{array}$

Could the kind of missing NPs we are concerned with, the kind illustrated in the gloss of the text in (2) (and see Appendix I) or the kind occurring in the control structures we have just reviewed, fall into this typology?

The answer, I suggest, is no. First, we can discount the possibility that any NP-gaps in Guugu Yimidhirr are NP-traces: for in a language with free word order, NP-movement can not sensibly be detected, and since constituents have no canonical sites (as far as GRAMMAR is concerned, which is not to say that there are not favoured word orders), they can leave no 'traces' in them, as it were. ${ }^{24}$ In any case, we are concerned with NPs that are not just misplaced but missing altogether: we know they are 'missing' because there is regular verb subcategorization in Guugu Yimidhirr, controlling the case-realization of overt NPs, and making, for example, a precise distinction between transitive verbs (which accept the reflexive suffix) and intransitive verbs (which do not; Haviland, 1979a: 78-79).

By the same argument, there can be no evidence for Wh-movement or

[23] One notable exception appears to be a constraint on the deletion of the object of a purposive clause under identity with the subject of an intransitive matrix clause (Haviland, 1979a: 136). Since this is a rare pattern of co-reference, the constraint may be pragmatic, in the sense that deletion would suggest other more common patterns of co-reference.

[24] There is an important class of possible exceptions to this statement. Guugu Yimidhirr sentences occasionally, but recurrently, exhibit not only word-order scrambling within clauses, but also across clauses, e.g. from a subordinate purposive clause into a matrix clause (see example in footnote II). In the latter cases, we can perhaps attempt to justify talk of NP-movement. Even here though we might be well advised to permit random order at the syntactic level, requiring some rule of interpretation linking subcategorized but unfilled theta-roles (or valents) in one clause with supernumerary (unsubcategorized) valents in another. 
Topicalization in single clauses, and thus no evidence for treating gaps in single clause sentences as variables. Leaving aside cross-clause Wh-movement (which doesn't seem to occur), in cross-clause NP-movement, which might perhaps be treated as Topicalization, Guugu Yimidhirr would fail the crucial diagnostics for variable-binding like the 'Strong Crossover Condition' (van Riemsdijk \& Williams, (1986: $209 \mathrm{ff}$ ); Xu (1986: 77-82) illustrates the failure for Chinese in a way that Guugu Yimidhirr would, I believe, parallel). And in any case, the kinds of gaps we are primarily concerned with here are, to repeat, missing valents and not merely displaced ones.

Thus the sole remaining candidates for our NP-gaps are PRO and pro. But the preceding section has already undermined the basis for a distinction between two such empty categories in Guugu Yimidhirr, the one governed and the other ungoverned, occurring in two distinct structural loci. Since there seem to be no locations where NP-gaps are obligatory (unlike e.g. in English subjectless infinitives) and since whenever NPs appear in these possible gap-locations they are invariably governed and case-assigned, the structural conditions for such a distinction are absent.

Of course, the distinction could be absent because ALL the gaps are of the same one type, but that type is either PRO or pro. Suppose they were all PRO: then the missing valents we are concerned with should not routinely be direct objects (since that position is always governed and case-marked) but they are. Moreover, we can even show (as Simpson \& Bresnan (1983) did for Warlpiri) that there is some reason to suppose that the missing element is itself case-marked - for example, adjectives modifying missing head nouns will bear the same case that the noun would have were it overt. ${ }^{25}$ Further, if the missing elements were PRO, they should be subject to strict control in control-structures - but they are only preferentially interpreted in a coreferential way, as established in the prior section. Let us therefore consider the much more plausible alternative that all these NP-gaps are to be identified with pro, i.e. a null pronoun.

Xu (1986), going through a similar attempt to relate Chinese NP-gaps to GB empty categories, tries to show with some ingenuity that at least some of the Chinese NP-gaps are distinct in grammatical category and semantic construal from overt pronouns, and thus that the class of gaps as a whole cannot be identified with a null pronominal, pro. First, he shows that the NP-gaps and overt pronouns do not have the same range of distribution

[25] For example, in Appendix 1, 1. 173, we have:

$$
\begin{aligned}
& \text { maani yindu } \\
& \emptyset \text { get-PAST other-ABS } \\
& \text { '(he) grabbed one (of them)' }
\end{aligned}
$$

where yindu is an adjective in Absolutive case modifying a missing object of the transitive verb. 
(although there is considerable overlap). An example that seems equally to hold for Guugu Yimidhirr is that various nominal sentences (expressed as two NPs without a verb), like identity statements, require two overt NPs; where one of these is pronominal it could not be replaced by a zero-anaphor or gap. ${ }^{26}$ Secondly, in Chinese there are two interesting differences of construal distinguishing overt pronouns and gaps: the gaps, but not the pronouns, admit of a quantifier-variable interpretation, and a reflexive interpretation. For example, in the pair of Chinese sentences glossing 'Everybody wishes that $\{$ he/zero\} can be happy', the overt pronoun will resist a variable reading and invite a reading where 'he' is some one particular individual, say John (Xu, 1986: 86-87). There may be some analogue of this in Guugu Yimidhirr but the matter requires further investigation. ${ }^{27}$ In any case, the pragmatic apparatus to be developed below in fact predicts that, where a language offers a systematic choice of overt pronoun and gap, the overt pronoun will implicate disjunctive reference; thus this Chinese (and possible Guugu Yimidhirr) pattern of interpretation may be a pragmatic rather than a grammatical fact. The Chinese possibility of reflexive interpretations of gaps probably has no Guugu Yimidhirr analogue, but in any case the Chinese examples depend on precise discourse contexts and thus, arguably, on discourse ellipsis.

I do not have the Guugu Yimidhirr data to parallel Xu's argument for Chinese in any detail, but what I do have (like the identity statements) suggests that parallel arguments may be possible. However, since the pragmatic apparatus below predicts contrastive uses of NP-gaps and pronouns, it suggests that it will be no easy matter to distinguish a syntactic, as opposed to a pragmatic, basis for a distinction between overt and covert pronouns. Thus the 'all gaps = pro' hypothesis is only weakly undermined by the argument so far; but however important the hypothesis might be to GB theories of Universal Grammar, it is simply rather uninteresting as far as Guugu Yimidhirr is concerned, as there will be no opposition to other kinds of gaps with contrastive properties.

There is one additional argument, though, against identifying Guugu Yimidhirr NP-gaps with pro. For, whereas personal pronouns are necessarily semantically definite, NP-gaps in Guugu Yimidhirr can be indefinite, glossing

[26] For a Guugu Yimidhirr example, see Appendix 1, line 172, and gloss in Appendix 2 in the text above. Note that this example occurs just after a reference to the same referent by a zero, thus if that 'deletion' were possible in this identity statement, we would here expect it.

[27] Haviland, p.c., thinks that the argument does not directly translate into Guugu Yimidhirr. For example, a sentence like the following would seem to admit the same variable interpretation whether or not the bracketed pronoun is overt or 'deleted':

$\begin{array}{lllll}\text { dhana } & \text { wulbu } & \text { wawu-dhirr } & \text { (dhana) } & \text { dhada-nhu } \\ \text { they-NOM } & \text { all-ABS } & \text { soul-COMIT } & \text { [they-NOM } & \text { go-PURP] }\end{array}$

'They all want (themselves) to go' 
as 'someone', 'something', etc. Thus a standard way to say 'someone killed the cow' would be minha gunday '(zero) meat/animal killed'; and a pronoun in the gap would rule out that indefinite interpretation. Further, indefinites of the sort glossing 'whoever', 'whatever', etc., are overtly expressed in Guugu Yimidhirr by the same morphemes used for Wh-words: for example, wanhu glosses as both 'who?' and 'whoever' (Haviland, 1979a: 69-72). Wh-words are, by GB hypothesis, of distinct grammatical category from personal pronouns. Thus either the NP-gaps we are considering are of a more inclusive grammatical category than pro, or there are in fact two kinds of Guugu Yimidhirr NP-gaps: covert pronominals and covert indefinites more closely allied to Wh-words. But there is no evidence whatsoever for the latter hypothesis, as the indefinite interpretations arise in the same structures as the definite ones, but simply where there is no salient definite reference given by earlier NPs that can be happily construed (given contextual assumptions) with the gaps in question.

The evidence thus collectively points to the failure of any identity between Guugu Yimidhirr NP-gaps and the GB empty categories. On the available evidence, Guugu Yimidhirr gaps seem to form a syntactically undifferentiated class that subsumes the functions of PRO and pro in particular, indefinites and sometimes probably quantified variables as well. Xu (I986: 91), considering the GB theorist's options to the somewhat similar situation in Chinese, concludes that although we could set up a new general type of empty syntactic category (he suggests the term 'free empty category') and consider the choice between the four specific GB empty categories and the one 'free empty category' to be a parameter in Universal Grammar, we might equally just as well consider that in languages like Chinese, and we may now add Guugu Yimidhirr, there are no underlying entities of any sort, just missing exponents of Theta-roles to be supplied by pragmatic construal. ${ }^{28}$

\subsection{Conclusions re Control and Binding in Guugu Yimidhirr}

Let us summarize so far. In Guugu Yimidhirr, as far as the Binding of different categories of NP is concerned, the central fact seems to be that the reflexive/antipassive construction pre-empts co-referentiality between NPs with different Theta-roles in the same clause - that is to say, co-referentiality between clause-mate core arguments with distinct grammatical function can only be expressed using the reflexive. Given this, NPs are not interpreted as co-referential with other NPs within the same clause, whether those NPs are lexical, pronominal or gaps (unless they occur within adjunct, e.g. Genitive or Locative, NPs). Across clauses (from matrix to subordinate), though, lexical NPs may co-refer in contrast to English, and of course gaps and

[28] A consequence of this latter view, of course, is that verb-subcategorization must be seen as an entirely semantic, not a syntactic, affair; that consequence is, though, in line with assumptions made, e.g. by Hale, about the nature of $\mathrm{W}^{*}$ languages. 
pronouns may also do so, as in English, but without the structural constraints typical of English. Thus the particular typology of NP types, with a parallel typology of gaps, that is required by GB theory seems to be inapplicable to Guugu Yimidhirr. Given the reflexive/antipassive, the rest of the facts will turn out to be accountable by pragmatic theories of preferred interpretation, to which we will turn in the next section.

As regards the theory of Control, we have seen that there are distinct parallels in Guugu Yimidhirr to the control phenomena in English, and the generalizations follow the prediction by Foley \& Van Valin (1983), namely volitional and commissive predicates prefer subject control, directive predicates prefer object control. However, in most of these structures the controlled NP need not be null, though it normally is, both controlling and controlled NPs may be null, the co-referential (controlled) interpretation of the null NP in the subordinate clause is probably only preferential in most if not all of the constructions, and finally none of the constructions appear to require co-referentiality between matrix and subordinate NPs. The facts thus seem to suggest a semantic/pragmatic rather than a grammatical explanation (with the possible exception of a constraint against the deletion of the object of a purposive clause under coreferentiality with a matrix NP in S-function; discussed by Haviland, I979a: 136.)

Finally, we have seen that the missing valents that are the focus of our concern do not easily equate with any of the four types of empty category provided by GB theory: rather they seem to be syntactically undifferentiated, indeed gaps rather than empty syntactic categories, that allow a wide range of interpretations.

\section{Pragmatic Principles of informativeness}

Pragmatic principles should, by their very nature, have general application it is this that gives them their explanatory power. By the same token, we are not free to invent ad hoc pragmatic principles to deal with specific problems. Therefore, I shall try here to establish that the principles required to deal with the patterns of preferred interpretations for lexical NPs, pronouns and gaps have their bias in much more general patterns of preferred interpretation. ${ }^{29}$ In fact, I shall argue, they are merely instantiations of the classical Gricean generalized conversational implicatures. Specifically, the effects are obtained from the systematic interaction of the two maxims of Quantity and a maxim of Manner, all interpreted, it has to be admitted, somewhat neo-classically.

The maxims of Quantity have, of course, to do with quantity of information, and in Grice's somewhat casual formulation they go as follows (Grice, 1975: 45-46):

[29] Elsewhere (Levinson, 1987) I have adduced another kind of evidence for these principles, namely patterns of preferred interpretation indicated by much prior work on conversational data. 
(27) Quantity I: 'Make your contribution as informative as is required (for the current purposes of the exchange)';

Quantity 2: 'Do not make your contribution more informative than is required'.

Grice went on to raise the doubt that Quantity 2 was actually required, since its effects might be achieved by the maxim of Relevance (superfluity of information rendering itself irrelevant). Recently, however, it has been argued by Atlas \& Levinson (I98I), Horn (I985), and Sperber \& Wilson (I986) that we do in fact need a principle that achieves the effects of Quantity 2. Both Horn and Sperber \& Wilson independently identify this principle with Relevance (for the reasons that Grice hinted), but this is, I believe, mistaken, for (pretheoretically, anyway) relevance is not primarily about information relevance is a measure of timely helpfulness with respect to interactional goals. However, that particular controversy need not concern us here; what is pertinent is the evidence for, and the nature of, the maxims governing information. For neutrality, I will call Quantity 2 the Principle of Informativeness or the I-principle (following Atlas \& Levinson, 198I), referring to the first maxim of Quantity as the Q-principle.

Let us start by fleshing out the Gricean formulations. To avoid confusion it is essential to distinguish, for each principle, a speaker's maxim and the corresponding recipient's corollary. The following is a first approximation for the Q-principle:

(28) Q-principle

Speaker's Maxim: Do not provide a statement that is informationally weaker than your knowledge of the world allows, unless providing a stronger statement would contravene the I-principle.

Recipient's Corollary: Take it that the speaker made the strongest statement consistent with what he knows, and therefore that:

(a) if the speaker asserted $\mathrm{A}(\mathrm{W})$, and $\langle\mathrm{S}, \mathrm{W}\rangle$ form a Horn scale (such that $A(S) \vdash A(W)$ ), then one can infer $K \sim(A(S)$ ), i.e. that the speaker knows that the stronger statement would be false;

(b) if the speaker asserted $A(W)$ and $A(W)$ fails to entail an embedded sentence $Q$, which a stronger statement $A(S)$ would entail, and $\{S, W\}$ form a contrast set, then one can infer $\sim \mathrm{K}(\mathrm{Q})$, i.e. the speaker does not know whether $\mathrm{Q}$ obtains or not.

The hearer's corollary will induce the well-known generalized Quantity implicatures discussed by Horn (1972) and Gazdar (1979) in particular. Thus, from the assertion of the (a) sentences below, we obtain the (b) implicatures:

(29) (a) Some of my best friends are linguists

(b) Not all of my best friends are linguists 
(30) (a) John believes there is life on Mars

(b) John doesn't know that there is life on Mars

These are well attested and widely discussed (see e.g. Levinson, 1983); however, the nature of the contrast sets that induce them is not well understood, a matter I discuss elsewhere. But the relevant point to notice here is that Q-implicatures enrich utterance meaning just by inducing the negation of a stronger possible proposition.

Let is turn now to the less well established I-principle:

(31) I-Principle

Speaker's Maxim: the Maxim of Minimization

'Say as little as necessary', i.e. produce the minimal linguistic information sufficient to achieve your communicational ends (bearing the Q-principle in mind).

Recipient's Corollary: the Enrichment Rule

Amplify the informational content of the speaker's utterance, by finding the most SPECIFIC interpretation, up to what you judge to be the speaker's $m$-intended point.

Specifically:

(a) Assume that stereotypical relations obtain between referents or events, UNLESS (i) this is inconsistent with what is taken for granted, (ii) the speaker has broken the maxim of Minimization by choosing a prolix expression.

(b) Assume the existence or actuality of what a sentence is 'about' if that is consistent with what is taken for granted.

(c) Avoid interpretations that multiply entities referred to (assume referential parsimony); specifically, prefer coreferential readings of reduced NPs (pronouns or zeros).

The I-principle has the following obvious but far-reaching consequence: a speaker's maxim of Minimization ('say as little as necessary') has as immediate corollary an addressee's maxim of INFERENTIAL MAXIMIZATION. Thus there arises a potential paradox, in slogan form 'the less you say, the more you mean'. In practice, this amounts to a preference for the maximally rich interpretation of minimal, informationally reduced, forms.

There are some difficulties with the notion of 'minimization' here, to which I but allude (see Levinson, 1987). There are two distinct concepts involved: (i) semantic minimization, which is equivalent to semantic generality, so that e.g. a pronoun is nearly always less semantically specific (more 'minimal') than a lexical NP; and (ii) expression minimization, which is some (no doubt complex) measure of surface length and complexity (or, if one prefers, some quantification over units of speech production). A quite good Zipfian 
argument can be made to the effect that these will tend to conflate. ${ }^{30}$ For our purposes, it will be sufficient to note that there is a hierarchy in both informational and (generally) in surface minimization between three types of NP realization:

\section{Lexical NP > Pronoun $>$ Zero Anaphor}

The lexical NP will tend to be less minimal both semantically and phonetically than the pronoun, and the pronoun (encoding number, etc.) less minimal than the NP-gap. I shall therefore let our principle of minimization operate over both kinds of minimization, noting that there may in fact be a covert reference to the maxims of Manner here.

The evidence for the existence of something like the I-principle comes from many different kinds of informationally ampliative conversational inferences. Here are some (where the (a) utterances will tend to implicate the (b) propositions):

(32) 'Conjunction buttressing' (Atlas \& Levinson, 198I)
(a) John turned the key and the engine started
(b) $\mathrm{p}$ and then $\mathrm{q}$ (temporal sequence)
$p$ therefore $q$ (causal connectedness)
A did $\mathrm{X}$ in order to cause q (teleology, intentionality)

(33) 'Conditional perfection' (Geis \& Zwicky, 1971)
(a) If you mow the lawn, I'll give you $\$ 5$
(b) If and only if you mow the lawn, will I give you $\$ 5$

(34) 'Bridging' (Clark \& Haviland, 1977)

(a) John unpacked the picnic. The beer was warm.

(b) The beer was part of the picnic.

(35) 'Inference to stereotype' (Atlas \& Levinson, 198I)

(a) John said 'Hello' to the secretary and then he smiled

(b) John said 'Hello' to the female secretary and then he John smiled

(36) 'Mirror maxim' (Harnish, 1976: 359)

(a) Harry and Sue bought a piano

(b) They bought it together, not one each

(37) Preferred Co-reference

(a) John came in and he sat down

(b) John $\mathrm{J}_{1}$ came in and he $\mathrm{H}_{1}$ sat down

[30] The argument is simple enough: the first premise is Zipf's Law of Abbreviation ("the more use, the shorter'); the second premise is his Principle of Economic Versatility ('the more semantically general, the more use'); the conclusion is 'the more semantically general, the shorter'. See Zipf, 1949; Horn, 1985: 30; also, Haiman, 1985: Part II. 
Many other examples of inferential informational enrichment could be adduced, including for example 'frame' based inferences (e.g. Charniak, 1972). The (b) instantiation of the recipient's enrichment rule above was designed to handle the rich presuppositional readings of utterances, but I shall say nothing more about that here (see Atlas \& Levinson, $198 \mathrm{I}$ ). It is the (c) instantiation that will be of special interest here: it is designed to predict the preference for co-referential readings of utterances.

It is clear that many of these inferences rely on detailed mechanisms of restricted application, but they do share some important properties: (a) the inferences are more informative than the utterances that give rise to them - the implicated propositions entail the sentences that give rise to them but not vice-versa; (b) the implicated propositions are more precise or specific than the corresponding sentences (not more informative, e.g. merely by the conjunction of unrelated propositions); they take one from a semantically general meaning to a pragmatically specific or precise interpretation; (c) these I-inferences differ from Q-inferences which also increase the informativeness of utterances in that the latter do so only by the negation of a stronger proposition that might have been directly expressed but was not.

The claim that the I-principle induces more informative and more precise or specific interpretations of utterances obviously requires a characterization of relative informativeness and specificity. These notions are well known to be fairly intractable. One solution is to adopt, partly for lack of serious alternatives, the analysis of informativeness due to Bar-Hillel and Carnap (1952) which is one way of operationalizing the Popperian idea of informativeness-relative-to-falsifiability: the greater the number of possible state-descriptions that are ruled out by (are incompatible with) a proposition, the more informative it is. ${ }^{31}$ This will have as a consequence (Bar-Hillel \& Carnap, 1952: $227 \mathrm{ff}$.) the simple entailment analysis of informativeness that underlies the Horn-scales involved in the Q-implicatures:

(38) a proposition A is MORE INFORMATIVE than a proposition $B$ iff the set of entailments of $B$ is properly contained in the set of entailments of $\mathrm{A}$.

Now, the method of state-descriptions suggests one way in which we might derive, or theoretically predict, the empirically observable preference for co-referential interpretations outlined in Condition (c) of the I-principle in (3I) above. (Without such a theoretical argument, linking the preference for co-referential interpretations to the I-principle, we will have to state condition (c) as an independent pragmatic principle.) The argument would go as follows: a co-referential interpretation reduces the number of entities required in the domain of discourse, i.e. the interpretation can proceed on a smaller domain of discourse than it could on a non-co-referential interpretation. But

[31] Popper's ideas were apparently independent, however, (Bar-Hillel, 1964: 10). 
if the set of entities in the domain of discourse is smaller, so too will be the number of state-descriptions compatible with the assertion in question..$^{32}$ Thus the assertion will be, from an extensional point of view, less 'general' (compatible with less possible states of affairs) and thus more specific and informative on the assumption of the minimal possible domain of discourse. Hence the preference for co-referential interpretations is properly a part of the I-principle. ${ }^{33}$

Popper independently offers us another argument (I 959:68 ff.): existential statements are weak - they are not falsifiable by any single observation; consequently, the fewer existential commitments the stronger the 'theory' (read 'assertion' for our purposes). Consider, for example, the two interpretations of the same sentence indicated below:

(a) John loved his $_{1}$ father

(b) John ${ }_{1}$ loved his ${ }_{2}$ father

On Popper's view the logical forms would be something like the following, respectively:

$\left(a^{\prime}\right) \quad \exists x$ [LOVE $\left.(x, \iota z(F(z, x))) \& x=J o h n\right]$

i.e. There's an $x$ such that $x$ loves the unique $z$ which is father of $x$, and $x$ is John

(b') $\exists x \exists y$ [LOVE $(x, \iota z(F(z, y))) \& x \neq y \& x=J o h n]$

i.e. There's an $x$ and a $y$ such that $x$ loves the unique $z$ who is father of $y$, and $y$ is distinct from $x$, and $x$ is John.

Given the principle, 'the more existential quantifiers, the less informative the statement', the interpretation in (a) is clearly to be preferred by the I-principle to the interpretation in (b). Thus the preference for co-referential interpretations can be seen to follow naturally from the I-principle on this Popperian

[32] Let me illustrate. Given two predicates, $M \& Y$, and one entity $a, M(a)$ will be compatible with just two state-descriptions, (i) $\mathrm{M}$ (a) \& $\mathrm{Y}$ (a), (ii) $\mathrm{M}$ (a) \& $\sim \mathrm{Y}$ (a); but given two entities, $a$ and $b, M(a)$ will be compatible with eight state-descriptions, as the reader may verify. Thus, in the latter case, M(a) will be semantically general over eight possible states of affairs. Enlarging the domain to three individuals will yield 16 compatible state descriptions, etc. Unfortunately, Bar-Hillel does not seem to have explored the effect of relative size of domain of discourse on his concepts of semantic informativeness, so some foundational work would need to be done to make sense of this; it would appear, for instance, that the PROPORTION of compatible to incompatible state descriptions for a given assertion stays constant whatever the size of the domain of discourse, and there may be some interesting theorems in this area.

[33] Jay Atlas points out various limitations of this argument. First, the state-description account of informativeness holds only (as Bar-Hillel \& Carnap admitted) if the language excludes identity and contains no co-extensive expressions. Secondly, the size of the domain of discourse will be irrelevant to the informational content of non-contingent statements, but this is perhaps as it should be. Finally, and most importantly, the notion of informativeness (call it D-informativeness) introduced by the size-of-domain argument is not a concept concerning the informativeness of a sentence $S$, it is a concept concerning the informativeness of a sentence-relative-to-a-world: thus D-informativeness is a threeplace relation - ' $S$ is more $D$-informative in world $A$ than in world $B$ '. 
account. ${ }^{34}$ Some differences between these two accounts are worth pointing out. Notice that the Carnapian argument is at the level of reference; it is an argument favouring the assumption of parsimony in reference - it might be glossed 'for interpretation, choose a domain (D) or world (compatible with all one knows) that makes a statement most specific, and thus maximizes D-informativeness'. The Popperian argument assumes that the domain of discourse is held constant, and offers an evaluation for alternative statements that a sentence might have been used to make - it might be glossed 'choose the logical form (or set of truth-conditions, or proposition expressed) that minimizes existential commitment and thus maximizes P-informativeness'. It is thus an argument essentially at the level of logical form, although since it involves the referential apparatus of existential quantification, it is also an argument at the level of reference.

There may be other ways in which to derive the preference for co-referential readings from the Principle of Informativeness. If both of the above arguments are partially at the level of reference, another argument is at the level of sense. In John came in and he sat down, regardless of the domain of discourse, the co-referential reading is obviously more informative ABOUT JoHN. Indeed the co-referential reading is more informative about John than the non-co-referential reading would be about either referent; it is likely therefore to be a better, more informative interpretation..$^{35}$

I shall assume that at least one of these arguments, and possibly a conjunction of them, is sound, and that we may thus derive the preference for co-referential readings from the general I-principle. ${ }^{36}$ And in any case I

[34] I am most grateful to Jay Atlas for explaining the force of the Popperian analysis to me. Notice that this account, unlike the Carnapian one of D-informativeness (as outlined in the prior footnote), is independent of the size of the domain of discourse. It offers an account of the relative informativeness (call if $\mathrm{P}$-informativeness) of a logical form attributable to a sentence, irrespective of the domain of quantification. It is thus a two-place relation: of two logical forms, $L$ and $M$, each assignable to sentence $S, L$ is more P-informative than $\mathrm{M}$.

[35] Once again, I owe this argument, or at least a version of it, to Jay Atlas. I am not sure that it is sufficient without the other arguments that support the assumption of referential parsimony. One doubt that naturally arises, though, is easily enough dissipated (courtesy Atlas again): surely, it might be argued, an addressee might prefer a little information about two referents to a lot of information about one referent? Well, of course, so he might: but that is to invoke yet another concept of informativeness, informativeness-for-a-person (in a particular state of knowledge), which is of course a matter entirely relative to context. But that is exactly NOT what is theoretically required here: we need an account of a default preference for a particular interpretation of a sentence - it is a notion of statementinformativeness that we are after, not speaker- (or hearer-) informativeness.

[36] Incidentally, we shall make use of another argument at the level of sense below, namely that a sentence with a reflexive pronoun (and thus entailed co-reference) is more informative than the corresponding sentence with a non-reflexive pronoun (grammatically unconstrained in reference). This is because the non-reflexive pronoun is, in most locations anyway, semantically unconstrained in reference (beyond the language-specific person/ number/gender characteristics encoded); further, and perhaps less intuitively, it may be claimed that the reflexive sentence actually entails the corresponding non-reflexive, since the former merely has an additional compatible component of sense, namely coreference - see footnote 38 . 
take that preference to be an empirical fact, whatever the success of this theoretical account.

It should be fairly obvious that the Q-principle and the I-principle appear to work in opposing directions: the Q-principle induces the inference of the negation of a stronger reading from the use of a weaker (informationally less rich) expression, while the I-principle induces a stronger interpretation from the use of a less specific, semantically general expression. It is clear, I hope, from the examples, that this clash is not just a theoretical inconsistency, but a genuine empirical puzzle. An example may clarify the point: we have already noted the I-inference to temporal sequences, causality and teleology in conjunctions of two events, like:

(39) John turned the key and the engine started

Now, the Q-principle appears to make exactly the opposite prediction: (i) there is a stronger expression that would express sequentiality and causality, namely:

(40) Since John turned the key, the engine started

(ii) the speaker has not said it; (iii) therefore, he cannot be in an epistemic position to say it, and he intends to implicate that there is no temporal or causal connection between the two events. This is, of course, exactly the wrong prediction, and our problem is to understand why the Q-principle does not operate in cases like this. Trying to understand this, Atlas \& Levinson (198I) noted that the Q-principle is of quite restricted scope. It operates only on clearly defined contrast sets, of which the Horn scale is prototypical. For two linguistic expressions $S$ and $W$, where $S$ is informationally richer than $\mathrm{W}$, to constitute a Horn scale the following constraints must be met: ${ }^{37}$

(4I) Constraints on Horn scales

For $\langle\mathrm{S}, \mathrm{W}\rangle$ to form a Horn scale,

(i) $\mathrm{A}(\mathrm{S})$ must entail $\mathrm{A}(\mathrm{W})$ for some arbitrary sentence frame $\mathrm{A}$;

(ii) S and W must be EQUALLY LEXICALIZED (hence no Horn scale $\langle$ iff, if $>$ to block 'conditional perfection');

(iii) S and W must be 'ABOUT' THE SAME SEMANTIC RELATIONS, or from the same semantic field (hence no scale $\langle$ since, and $\rangle$ to block 'conjunction buttressing')

When thus properly constrained, the apparent anomaly of two antinomic principles partly disappears. Thus in the case of why an utterance of the form $p$ and $q$ does not implicate 'not (since $\mathrm{p}, \mathrm{q}$ )', our explanation is that there is no such scale 〈since, and) for Q-implicatures to be derived from. The anomaly is further reduced by the general principle that implicatures are

[37] I have to confess to some doubts that these conditions are sufficient; they may also not be necessary, as they may be somewhat too strong, but the constraints seem to be along the right lines. 
defeasible in the face of inconsistent assumptions (Gazdar, 1979): if the door is locked I have a key in my pocket does not undergo 'conditional perfection' to 'iff' because this would be inconsistent with our assumption that keys do not translocate to pockets when doors are locked. However, as a matter of empirical fact, where there is a genuine clash, Q-implicatures appear to override I-implicatures (Atlas \& Levinson, I98 I : $43 \mathrm{ff}$.).

Now, Horn (1985), considering the interaction of the I- and Q-principles thought he saw another resolution to the clash between them, which he called the Pragmatic Division of Labour. I outline the idea below (I have designated his Q-implicatures 'Q/M-implicatures' for reasons that will be made clear below):

(42) Horn's Pragmatic Division of Labour

(a) The I-principle (Horn's R-principle) induces stereotypical interpretations: if a simple, unmarked expression $U$ denotes the set of extensions $\mathrm{E}, \mathrm{U}$ will tend to become associated with the stereotypical subset $F$ of $E$. For example, secretary will I-implicate 'female secretary', drink 'alcoholic drink', road 'metalled road', etc.

(b) The Q/M-corollary: if U I-implicates restriction to subset $\mathrm{F}$, then the use of an alternative, unusual, marked or more prolix expression $\mathrm{M}$ will $\mathrm{Q} / \mathrm{M}$-implicate the complement of $\mathrm{F}$, the non-stereotypical subset $\mathrm{G}$ of extensions $\mathrm{E}$. For example, amanuensis will Q-implicate 'male secretary', beverage will $\mathrm{Q} / \mathrm{M}$-implicate 'non-alcoholic drink', track will Q/M-implicate 'non-metalled road'.

Horn points out that this interaction has considerable application to both diachronic semantics and synchronic pragmatics. Consider the contrast between the following pair of sentences:

(43) (a) Larry stopped the car

(b) Larry caused the car to stop

The lexical causative suggests that the car was stopped in the stereotypical way, by means of the brake pedal; the periphrastic causative suggests that the action was done in some less usual way, e.g. by means of the handbrake. Similarly for the following, the non-equivalence of which has long been noted (Jespersen, 1924; discussed in Horn, 1985: 31):

(44) (a) The bus comes often

(b) The bus comes not infrequently

the former I-implicating (by stereotypical expectations dependent on context), say, the arrival of a bus every half-hour or so, while the double negative 
form in the latter $\mathrm{Q} / \mathrm{M}$-implicates the inapplicability of the I-implicature (thus suggesting a much poorer service, say, every hour and a half). Or consider:

(45) (a) John could solve the problem

(b) John had the ability to solve the problem

where the former I-implicates that John solved the problem, the latter $\mathrm{Q} / \mathrm{M}$-implicates that John did not solve the problem.

However, it is clear that Horn is wrong to identify these Q/M-implicatures (his Q-implicatures) with Quantity implicatures. For the contrast involved in the Hornian division of labour is a contrast between marked and unmarked expressions, and more exactly a contrast between usual vs. unusual, or brief vs. prolix expressions. This distinction has nothing to do with quantity of information, the paired expressions being assumed to be synonymous; rather it has to do with surface form, and these implicatures are thus properly attributed to the maxim of Manner. The reason that Horn was led to think of the Q/M-implicatures as Quantity implicatures is that they display the same sort of underlying reasoning: given a pair of expressions, the use of the marked expression $\mathrm{Q} / \mathrm{M}$-implicates the inapplicability of the unmarked expression, just as the use of the informationally weaker expression Qimplicates the inapplicability of the paired stronger expression. We might therefore simply designate the $\mathrm{Q} / \mathrm{M}$-implicatures the $\mathbf{M}$-implicatures ( $\mathbf{M}$ for Manner), yet there is some reasoning from informational content: since the unmarked expression of such a pair I-implicates a richer, stereotypical interpretation, the use of the marked member Q-implicates the negation of the richer interpretation. Let me continue therefore to designate these implicatures the $\mathrm{Q} / \mathrm{M}$-implicatures.

We thus have three distinct kinds of implicature pertinent to our theme: Q-implicatures, I-implicatures and Q/M-implicatures. Clearly, such crosscutting principles would make for interpretive mayhem unless there is a system governing their interaction. As a first approximation, a simple order of precedence of application seems to resolve potential conflict:

(46) Interaction of the I-, Q- and Q/M-implicatures

(i) Genuine Q-implicatures from tight contrast sets of equally brief, equally lexicalized linguistic expressions 'about' the same semantic relations, take precedence over I-implicatures;

(ii) in all other cases the I-principle induces stereotypical specific interpretations, UNLESS:

(iii) there are two (or more) available expressions of the same sense, one of which is unmarked and the other marked in form. In that case, the unmarked form carries the I-implicatures as usual, but the use of the marked form Q/M-implicates the non-applicability of the pertinent I-implicatures. 
Clearly a system of this sort may appear baroque in contrast to the dual principles offered by Horn (1985) and especially the single principle offered by Sperber $\&$ Wilson (1986). I must leave the adjudication between these rival schemes to another paper (see also Levinson, 1987) but here it will be sufficient to note that the Sperber \& Wilson framework is specifically intended to deal with particularized conversational implicatures (and they confess to no interest in the Q-type implicatures at all), while the present account is restricted to generalized conversational implicatures - i.e. preferred interpretations in the absence of contextual cues to the contrary. Moreover, as I hope to show, it is the very interaction of multiple distinct principles that gives the present account its advantage over simpler schemes.

We are now in a position to see how the pattern of anaphoric reference I sketched in I.2 above can be seen to follow as a mere instantiation of general pragmatic principles. The pattern is, recollect, that given a choice between:

\section{Lexical NP $>$ Pronoun $>$ Zero}

a choice to the right will tend to implicate co-reference with another NP in the discourse in all loci where a reflexive could not have been used, while a contrastive choice to the left will tend to implicate a disjoint reading from another NP in the discourse that may otherwise be a possible antecedent. The pattern is generated by our principles as follows:

(a) Where the syntax permits a direct encoding of co-referentiality, e.g. by the use of a reflexive, the use of an informationally weaker expression, e.g. a non-reflexive pronoun, will Q-implicate a noncoreferential interpretation.

(b) Otherwise semantically general, minimally informative expressions (pronouns and gaps) will favour a co-referential interpretation by the I-principle, UNLESS:

(c) the use of a marked form, a lexical NP where a pronoun might have been used, or a pronoun where a zero might have occurred, will $\mathrm{Q} / \mathrm{M}$-implicate a non-co-referential interpretation.

We may now turn to consider the implications of such a pattern of preferred interpretations - two applications suggests themselves, (a) the explanation of patterns of preferred use in discourse, (b) the explanation of patterns of anaphora normally described in purely syntactic terms. It is the latter that will be the focus of the rest of this paper (but see Appendix I), although the central argument is that the two domains may not be after all so distinct. 


\section{SyNTAX AND ANAPHORA: PARTIAL PRAgMATIC REDUCTIONISM}

\section{I. English Binding and Control}

4.1. I English Binding. Wè now have an account of the following patterns of preferred interpretation:

(48) (a) John, likes him

(a') John 1 likes himself

(b) John 1 likes her 2 and he gave her $_{2}$ a valentine.

(b') *John 1 likes her 2 and himself gave her $_{2}$ a valentine

(c) John likes her 2 and the $\operatorname{man}_{3}$ gave her $_{2}$ a valentine.

Let me spell out the account:

(a) The use of the sentence in (48a) contrasts with the use of the reflexive as in $\left(\mathrm{a}^{\prime}\right)$. The alternates 〈himself, him > form a clear contrast set, and given our argument that co-referential sentences are more informative than the corresponding non-co-referential ones, a set ranked by informativeness. (The relative informativeness of the reflexive is due to the fact that the non-reflexive pronoun is, beyond gender-number-definiteness specification, entirely free in reference. $)^{38}$ Both the reflexive pronoun and the non-reflexive pronoun also satisfy the lexicalization constraint in (4I), so 〈himself, him > form a Horn scale. Thus the use of the non-reflexive sentence will induce a Q-implicature to the effect that the stronger or more informative statement does not hold; i.e. sentence (48a) Q-implicates disjoint reference.

(b) Q-implicatures can only arise where there is a possible alternation between a 'stronger' and 'weaker' expression, e.g. a reflexive vs. a nonreflexive pronoun. There is no such possibility in $\left(4^{8 b}\right) .\left(\left(b^{\prime}\right)\right.$ is ungramma-

[38] There is thus, it may be claimed, an implicational relationship between the reflexive and non-reflexive versions of the sentence; such a relation would have to hold at the level of semantic representation or logical form, rather than at the level of the proposition expressed by an utterance. Any intuition that 'John likes himself' does not imply 'John likes him' may then be attributed to the fact that him carries (at the level of utterance interpretation) the Q-implicature to disjoint reference. That the disjoint reference is a matter of implicature and not entailment would seem to be shown by the existence of exceptional co-referential usages of the pronoun, as in 'No-one else voted for Marcos, but at least Marcos voted for him ' or 'Ronald and Nancy have one thing in common: Nancy adores him and Ronald adores him t00' (see Evans, 1980; Reinhart, 1983: $168 \mathrm{ff}$.). As usual, it is defeasibility in particular that allows us to distinguish that which is entailed from that which is a generalized conversational implicature. See also (56) and related discussion below.

Without invoking an implicational relationship between reflexive and non-reflexive versions of a sentence, we might appeal directly to a Popperian argument, as follows. Sentence (b) below, on a non-coreferential interpretation, requires an additional existential quantifier to (a), as indicated by the associated logical forms:

(a) John likes himself

$\exists x[x=j \& L(x, x)]$

(b) John, likes him

$\exists \mathrm{x} \exists \mathrm{y}[\mathrm{x}=\mathrm{j} \& \mathrm{x} \neq \mathrm{y} \& \mathrm{~L}(\mathrm{x}, \mathrm{y})]$

The reflexive is thus more informative than an ordinary pronoun on a disjoint reading. 
tical.) In the absence of any Q-implicatures to block I-enrichment, the I-principle will induce co-reference in order to achieve parsimony in reference; any semantically general expressions, minimized in an informational sense, are (given the maxim of minimization) ripe for such I-enrichment (unless the $\mathrm{Q} / \mathrm{M}$ principle intervenes). Therefore, where person-number-gender features permit, pronouns should be interpreted co-referentially where possible, as in sentence $(48 \mathrm{~b})$.

(c) However, expressions of roughly equal semantic generality may contrast on the level of markedness of linguistic form (they may be periphrastic phrases, complex in derivational morphology, or non-idiomatic terms). Where there is such a set, and a marked form is employed, a Q/M-implicature will arise to suggest the complementary interpretation to the I-implicature that would have arisen from the use of the unmarked alternate. Thus the use of the man in sentence $(48 \mathrm{c})$ will induce a $\mathrm{Q} / \mathrm{M}$-implicature to nonco-referentiality, just where he would induce an I-implicature to co-referentiality.

However, as we all know, that is hardly the full story. Such a pure pragmatic account makes less than clear, even erroneous, predictions in the following kinds of alternation:

(49) (a) $\mathrm{John}_{1}$ thinks he $\mathrm{H}_{1 / 2}$ is a genius

(b) $\mathrm{He}_{1}$ thinks John $\mathrm{J}_{2}$ is a genius

(c) John's friends despise him hi/2 $_{1}$

(d) His friends despise John $_{1 / 2}$

Although one might claim that the disjoint reading of $(b)$ derives from the use of a marked NP following a pronoun (by our $\mathrm{Q} / \mathrm{M}$ principle), thus accounting for the difference between (a) (where I-enrichment is not blocked) and (b), yet there is no such contrast between (c) and (d). ${ }^{39}$

Enter grammar, and in particular Government and Binding Theory (Chomsky, I98I, 1982) and its derivatives. Recollect the three binding conditions, repeated here:

(50) Binding Conditions

A. 'Anaphors' (reflexives and reciprocals) must be bound in their minimal governing category

B. Pronouns must be free in their minimal governing category

C. Lexical NPs must be free everywhere.

('Bound' here, of course, means coindexed with a c-commanding argument, not 'semantically bound' in the sense to be discussed below.)

[39] Note that the pragmatic account would make essential use of sequential order in a way that I have not worked out. That order is a factor is evident from the relative success of the old 'precede and command' analyses of English 'pronominalization' (reviewed in Reinhart, 1983: I 3 ff.); and sheer sequential order looks, of course, more like a pragmatic than a grammatical parameter. But the point here is that order is not sufficient. 
It should be clear from the analysis of (48) that we now have A PARTIAL PRAGMATIC REDUCTION OF THESE CONDITIONS. At the risk of redundancy, let me spell it out:

(a) We accept Condition A as a rule of (English) grammar.

(b) Condition $B$ is then predicted (and rendered unnecessary) by the Q-principle as follows: wherever a reflexive (the semantically 'stronger' expression) could occur, the use of a pronoun (the semantically 'weaker' expression) will Q-implicate the inapplicability of a co-referential reading. We will thus obtain the complementary distribution of 'anaphors' and co-referentially interpretable pronouns, without invoking a separate Condition B. Where reflexives cannot occur, pronouns, being semantically general, will 1-implicate preferred co-referential interpretations (a pattern for which there is, quite properly, no GB account, it being clearly a matter of preferred interpretation).

(c) The pattern described in Condition $\mathrm{C}$ is the outcome of two pragmatic principles, the one applied to Condition A, the other to the pattern normally labelled Condition B. For the Q-principle, just as in the case of pronouns, will induce a non-co-referential interpretation whenever a lexical NP is used where a reflexive might have occurred (this alone would predict a similar distribution for pronouns and lexical NPs). However, in addition, the use of the more prolix or marked lexical NP where a reflexive could not have occurred, and thus where a pronoun would normally be subject to I-induced co-referentiality, will Q/M-implicate disjoint reference (thus distinguishing lexical NPs from pronouns in terms of distribution on co-referential interpretations).

Thus, a case can be made for the elimination of both Condition B and Condition $\mathrm{C}$ from principles of (universal) grammar, since their effects seem to be predicted by independently motivated pragmatic principles.

Such a reduction is, of course, far from wholly original: the mirror image relation between Condition $\mathrm{A}$ and $\mathrm{B}$ of the Binding Conditions invites a grammatical explanation of Condition $A$ and a pragmatic explanation of the complementary pattern in B. An early attempt was made by Dowty ( 1980 : $32 \mathrm{ff}$.) using a maxim of ambiguity-avoidance, ${ }^{40}$ and another much more carefully constructed account is made by Reinhart (1983), which dovetails closely with the present proposals.

[40] Dowty's principle can in fact be construed as an instantiation of our Q-principle: the use of a semantically general ('ambiguous') term where a semantically specific ('nonambiguous') term is in contrast will Q-implicate the inapplicability of the more specific, informationally rich term. Incidentally, Dowty (1980: 32-33) also points out why the possessive reflexives in English (e.g. his own) do not pragmatically contrast with the non-reflexive possessive pronouns: they do not fall under Binding Condition A (as shown by e.g. That is his own book), so there is no Q-implicated disjointness from the non-reflexive pronouns. 
Reinhart in effect adopts Binding Condition A (subsuming it within a general rule, discussed below). She then proposes an alleged maxim of Manner ' $\mathrm{Be}$ as explicit as the conditions permit' (1983: 167).

(51) (a) Joan adores her

(b) Joan adores herself

(c) Joan adores Joan

Given that Condition A will assure grammatical co-indexing in ( $5 \mathrm{I} b)$, any speaker who intends co-reference will be in breach of the explicitness maxim if he uses sentence ( $5 \mathrm{I}$ a), even though co-reference is not grammatically (but pragmatically) excluded in ( $5 \mathrm{r} a)$, on this account. Similarly, the reflexive pre-empts the co-referential reading of repeated lexical NPs as in (5I c). But of course, Reinhart's pragmatic principle appealed to here is not a maxim of Manner at all, for it induces an inference from the non-use of an informationally stronger expression (the reflexive) to the negation of that stronger interpretation - it is our now familiar Q-principle.

To handle the fact that in English there appear to be configurational constraints on lexical NP-pronoun co-reference, Reinhart treats all pronouns in a particular type of syntactic configuration as POTENTIALLY semantically bound, ${ }^{41}$ in the same way that quantifiers bind pronouns. Thus the following are seen as parallel:

(52) (a) All professors exploit their secretaries

(b) The professors exploit their secretaries

(c) The professors exploit their secretaries, and the administrators exploit theirs too

Clearly, $(52 \mathrm{~b})$ is ambiguous between a semantically bound interpretation as in (a) ('for each professor $x, x$ exploits $x$ 's secretary'), and a non-bound interpretation (as e.g. in 'the professors jointly exploit their collective pool of secretaries'); an ambiguity clearest perhaps in the sloppy identity context in (c). Only pronouns in certain configurations admit of the bound interpretation, namely if there is an NP that c-commands the pronoun outside that pronoun's minimal governing category. Such pronouns should of course be interpreted as bound by that NP, and thus co-indexed with it. Since reflexives/reciprocals are also interpreted as bound-variables, Reinhart sets up a single complex co-indexing rule which subsumes Binding Condition A (in my informal rephrasing of her account, 1983: 158):

(53) Reinhart's Co-indexing Rule

Grammatical Co-indexing permitted between italicized expressions only when:

[4I] I will use the phrase 'semantically bound' or 'quantifier-bound' to avoid ambiguity with the sense of 'bound' in the Binding Conditions, i.e. co-indexed with a c-commanding argument. 
I. A reflexive/reciprocal is c-commanded by an NP within its minimal governing category; (cf. Binding Condition A);

2. An ordinary pronoun is c-commanded by an NP outside its minimal governing category.

This rule applies optionally (the obligatory effect in the case of reflexives is obtained by an independent filter (1983: 159)).

The possibility of grammatical coindexing of a pronoun by a c-commanding NP explains the following patterns that seem to evade a purely pragmatic account (see Reinhart, 1983: Ch. 4) - note in particular that co-referential possibilities cannot be captured simply by linear order of lexical NP with respect to pronoun:

(54) (a) Zelda loves her $_{1 / 2}$ neighbours (co-reference possible)

(b) She ${ }_{1}$ loves Zelda's $s_{2}$ neighbours (co-reference impossible)

(c) Near him, Dan $_{1 / 2}$ saw a snake (co-reference possible)

(d) Near $\mathrm{Dan}_{1}$, he $_{2}$ saw a snake (co-reference impossible)

The grammatical co-indexing rule optionally applies only to (a) and (c) (where the lexical NPs c-command the pronouns). Thus, if a speaker intends the co-referential reading, he should use the form that (at least potentially) grammaticalizes co-reference; failure to use the stronger form will Q-implicate that the strong co-referential interpretation is not intended. Hence where pronouns c-command lexical NPs, the non-co-referential reading is strongly preferred (cf. Reinhart, 1983: 167).

Incidentally, pronouns, together with reflexives, co-indexed by the rule are in all cases interpreted by a single semantic rule which replaces them with bound variables within lambda-extracted predicates - informally (1983: I60):

(55) (a) Zelda loves her $_{1}$ neighbours

(a') Zelda ( $\lambda \times$ ( $x$ loves $x$ 's neighbours))

(b) Everyone ${ }_{1}$ upsets his ${ }_{1}$ neighbours

$\left(b^{\prime}\right)$ Everyone ( $\lambda \mathrm{x}$ ( $\mathrm{x}$ upsets $\mathrm{x}$ 's neighbours))

(c) Zelda ${ }_{1}$ loves herself ${ }_{1}$

(c') Zelda $(\lambda x$ ( $x$ loves $x)$ )

(d) Ann gives her pocket money to Oxfam, but Di gives it to Save the Children

(d') Ann ( $\lambda x$ ( $x$ gives $x$ 's pocket money to Oxfam) \& Di $(\lambda x$ ( $x$ gives $x$ 's pocket money to Save the Children))

This achieves a reduction of the half-dozen or so different kinds of pronoun usually described (bound, sloppy-identity as in (d), E-type, etc., see e.g. Kempson, forthcoming) to just two: semantically bound (subject to lambdaextraction) and referential pronouns (which may or may not be anaphoric).

Let us summarize: for English, we cannot simply take Binding Condition 
$A$ as the sole grammatical constraint on co-referentiality (deriving Condition $B$ and $C$ pragmatically), for there are the configurational effects as illustrated in (49) and (54). To obtain these, we need an additional grammatical rule for pronouns c-commanded by NPs (Reinhart's bound anaphora rule); once we have this, we can obtain the mirror-image pattern (where lexical NPs are c-commanded by pronouns these will be read as disjoint in reference) by the Q-principle.

The details of Reinhart's account are not perhaps essential to the present programme, although they dovetail to achieve a more or less descriptively adequate account of English (but see her list of residual problems, Ch. 8). The reliance on configurational constraints is likely to prove highly language dependent (as pointed out by Dowty, 1980). Another problem is that even bound-anaphora is not pragmatically immune, as Kempson (forthcoming) convincingly demonstrates. ${ }^{42}$ But Reinhart's idea that, WHATEVER the grammatical constraints on anaphora in a particular language, there will be complementary preferred pragmatic interpretations is certainly an important insight which will survive changes in both grammatical and pragmatic models of anaphora.

The advantage of a partially pragmatic account over the GB account is made clear by the exceptional usages that will always embarrass a purely grammatical explanation (Evans, 1980; Reinhart, 1983: I68 ff: Comrie, 1985):

(56) (a) Only Felix ${ }_{1}$ voted for Felix

(b) Only Felix 1 voted for himself

(c) Margaret's husband, is Dennis,

(d) Margaret's husband is himself

(e) Dennis and Margaret have one thing in common: Dennis thinks Margaret is terrific and Margaret thinks Margaret is terrific.

(f) Reagan ${ }_{1}$ said the President ${ }_{1}$ would sign the Bill

(g) The vendor ${ }_{1}$ absolves the vendor ${ }_{1}$ from all liability

(h) Frog went to Frog's house; Toad went to Toad's house

In (56), the (a) sentence violates Chomsky's Binding Condition C; it also appears to run counter to the Q-principle that will induce disjoint readings from non-reflexives where the reflexive can be used. However, (a) doesn't mean the same thing as (b): for (a) to be true Felix must have received only

[42] She points out that pragmatic 'bridging co-reference is involved in E-type sentences like Every KGB agent gets into a Yellow Cab to question the driver. To obtain an interpretation like the following we need to link the driver to Yellow Cab using background knowledge:

Every KGB agent ( $\lambda x$ (x gets into $x$ 's Yellow Cab) \& $(\lambda x$ (x questions the driver of $x$ 's Yellow Cab)

This sort of example is used by Kempson to argue for a pragmatic determination of logical form. 
one vote, but there is no such truth-condition in (b). Therefore, sentence (a) gives rise to no Q-implicature induced by the possibility of a stronger reflexive statement; and co-reference is preferred by the I-principle. Similarly, identity statements like (c) cannot be paraphrased by the reflexive formulation in (d), therefore again no Q-implicature to disjoint reference arises in (c). In case (e), in Margaret thinks [Margaret is terrific], the second NP is in a ccommanded position where a pronoun is subject to the bound-variable analysis; but, Reinhart (1983: 168-169) argues, what is topical is not having the property of finding oneself terrific - it is rather the property of finding Margaret terrific. So the bound-anaphora interpretation is not pertinent in this context, and again there is therefore no contrast between she and Margaret to induce a Q/M implicature to disjointness. Finally, it is quite clear that other pragmatic factors can licence co-referential readings of NPs that would normally Q- or Q/M-implicate disjointness. For example in (f), given the defeasibility of implicatures inconsistent with what is taken for granted, there will be no Q/M-implicature of disjointness from the use of the President in contrast to he-but there will be a $\mathrm{Q} / \mathrm{M}$-implicature to the distinction between the man and his office, which will justify the use of the more complex NP. And in (g) and (h), we simply have to face the fact that there are sociolinguistic registers and genres in which the maxim of minimization, and the correlative $\mathrm{Q} / \mathrm{M}$ implicatures, are simply not applied in the same way.

Thus, adopting Reinhart's account, and supplementing it with our three interacting principles, we achieve a partial reduction of the Binding Conditions: we retain an analogue of Condition $\mathrm{A}$, governing reflexives and reciprocals, and add a grammatical rule for bound anaphora; all other co-referential interpretations will be due to the I-principle, operating within sentences just as it does across sentences in so called 'discourse anaphora', while all disjoint interpretations will be induced either by a Q-principle contrast with a more informative alternate (reflexive or bound-anaphora) or by a $\mathrm{Q} / \mathrm{M}$ contrast between a reduced form (favouring co-referentiality by the I-principle) and the fuller, lexical NP actually used.

4.1.2. English Control. Let us now come back to the opposition between pronoun and zero form, as it shows up in the study of English infinitival complements. In Government and Binding Theory, there is of course a special sub-theory, the theory of control, to handle the interpretation of the zero-subject (designated PRO) of such infinitives. The classic problems concern the distinction between subject-controlling verbs as (57), and object-controlling verbs as in $\left(5^{8}\right)$ :

(57) $\mathrm{PRO}=$ 'Max' = Subject of Matrix

(a) Max tried [PRO to eat acorns]

(b) Max promised Sue [PRO to read the book]

(c) Max asked Mary [what PRO to do] 
(58) $\mathrm{PRO}=$ 'Sue' = Object of Matrix

(a) Max persuaded Sue [PRO to go]

(b) Max forced Sue [PRO to go]

(c) Max reminded Sue [PRO to go]

Jackendoff (I972), Radford (198I) and latterly Foley \& Van Valin (1983) have argued that these patterns are determined by the semantics of the verb. Thus Foley \& Van Valin argue that Subject-Control verbs are volitional or report commissive speech acts where, naturally enough, the agent is to do the infinitival action; while the Object-Control verbs are causatives or report directive speech acts (a kind of causative), where naturally the 'causee' or directed individual is to do the infinitival action.

However, there are some indications that this is not perhaps so firmly grammaticalized or semanticized; consider the following well-known cases where the interpretation varies not according to the verb but according to the most probable scenario:

(59) (a) Zelda 1 asked Mary $2\left[\mathrm{PRO}_{2}\right.$ to leave]

(b) Zelda $a_{1}$ asked [PRO ${ }_{1}$ to leave]

(c) John ${ }_{1}$ appealed to $\mathrm{Bill}_{2}\left[\mathrm{PRO}_{2}\right.$ to leave]

(d) John $n_{1}$ appealed to Bill ${ }_{2}\left[\mathrm{PRO}_{1}\right.$ to be allowed to leave]

(e) John ${ }_{1}$ needed a wife ${ }_{2}\left[\mathrm{PRO}_{1}\right.$ to frighten $]$

(f) John ${ }_{1}$ needed a wife $2\left[\mathrm{PRO}_{2}\right.$ to do the dishes]

(g) $\mathrm{John}_{1}$ needed a wife $2\left[\mathrm{PRO}_{1 / 2}\right.$ to entertain $]$

(g) $\mathrm{John}_{1}$ needed [PRO $\mathrm{PR}_{1}$ to do the dishes]

It is harder to find cases of such clear pragmatic determination of control with subject-control predicates like promise, but even here it is perhaps possible, and it certainly occurs in German and Russian (Comrie, $1985: 462$ ). ${ }^{43}$

What this suggests is that neither the syntax nor the semantics of the verb type strictly determines the interpretation of the NP-gap and that it might be a mistake to build 'control' into the grammar in the way done, for example, in GPSG (Gazdar, Klein, Pullum \& Sag, I985: $202 \mathrm{f}$ ). If it is built-in

[43] One area of pragmatic determination of control that has been neglected since the demise of the 'performative hypothesis' is control in imperatives like Please promise to come and suggestions like Why not ask to leave early? where the controlling NP (or antecedent for PRO) is on most modern accounts presumed to be pragmatically rather than syntactically given. In Guugu Yimidhirr, where the imperative is not restricted to second person interpretations, the pragmatic element is perhaps clearer - thus in the following sentence:

gad-ii [ngali [ngawiya-wi dhada-nhu]

come-IMP IDUAL turtle-LOC go-PURP

'Come for us to go for turtle'

i.e. 'Let us two go hunting for turtle'

the pronoun ngali could be omitted, in which case the dual first person interpretation of controller and controlled subject would be entirely pragmatic; alternatively another ngali could head the sentence to make both the controller and controlled NP explicit. 
then we will have to claim that the structures of the matrix verbs, are ambiguous i.e. distinct in each pair in (59)(a)/(b), (c)/(d), (e)/(f), etc. Instead, we seem to need a pragmatic determination of co-reference, guided by the verb semantics, along the following lines. Where the semantics of the verb, together with stereotypical scenarios, favours object-control, the I-principle will seek co-reference with an object-controller, but either finding no object (as in (59)(b) or (h)), or finding the requisite scenario incompatible with what is taken for granted $((59)(d)$, (e)), will try assigning co-reference to the residual possible controller, the subject. 'Obviative', 'indefinite' interpretations will occur where there is no NP to invite I-implicated coreference, as in (60a) below. However, as Chomsky puts it, "very loosely, it appears that PRO searches for a possible antecedent within its own clause, and if it cannot find one there, looks outside', normally preferring a subject (198I : 78). (These are admitted to be 'fairly loose requirements', possibly involving pragmatic factors (ibid. 79)). Thus we obtain 'long-range control' as in (6ob) (although, as we would expect on a pragmatic account, this is only a preferred interpretation):

(60) (a) It was difficult [PRO to fix]

(b) John $n_{1}$ found that it was difficult $\left[\mathrm{PRO}_{1}\right.$ to fix]

Let us now turn to just certain structures where PRO is in systematic opposition to an overt pronoun or lexical NP. Given GB theory, where PRO must not be governed while overt NPs must be governed in order to obtain case, the two will tend quite clearly to be in complementary distribution. There are just certain exceptional loci, as in the following:

(6I) (a) John wants PRO/him to come

(b) John is keen PRO/for him to come

(c) John likes PRO/his going away

So, in just these locations we have a possible contrast, PRO vs. overt pronoun. And we would expect the use of the more prolix overt pronoun to $Q / M$ implicate a referent disjoint from the PRO interpretation induced by the I-principle. And, as Chomsky notes, this is exactly what happens:

(62) (a) He'd $d_{1}$ prefer $\emptyset_{1}$ going

(b) $\mathrm{He}^{\prime} \mathrm{d}_{1}$ prefer his ${ }_{2}$ going (favoured interpretation)

(63) (a) $\mathrm{He}_{1}$ wants $\left[\mathrm{PRO}_{1}\right.$ to go]

(b) $\mathrm{He}_{1}$ wants [(for) him $\mathrm{h}_{2}$ to go]

(c) John $n_{1}$ bought a book $\left[\mathrm{PRO}_{1}\right.$ to give to Mary]

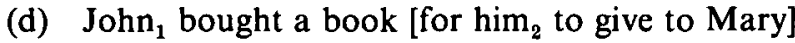

To account for these interpretations Chomsky invokes an 'Avoid Pronoun' Principle (1981 : 65), which specifies 'a choice of PRO over an overt pronoun where possible' - i.e. in structures where either PRO or pronoun may appear, 
the use of the pronoun implies disjoint reference. He adds that this Principle '... might be regarded as a subcase of a conversational principle of not saying more than is required, ... but there is some reason to believe it functions as a principle of grammar'. However, Horn points out the Avoid Pronoun Principle is entirely consonant with the I-principle [his R-principle] (I985:23) and his 'division of labour' between I and Q (1985:25). Moreover, we can now be a little more precise using our revised schema for Q- and I-principle interaction:

I. There is no Horn-scale 〈pronoun, PRO) giving rise to a $\mathrm{Q}-$ implicature which would prevent an I-implicature enriching the reduced form. ${ }^{44}$

2. The I-principle will induce a maximally informative interpretation of the reduced (PRO) structures, yielding the assumption of coreference wherever this is consistent with what is taken for granted.

3. Where, in contrast, a more prolix form (the pronoun) is employed, this will $\mathbf{Q} / \mathbf{M}$-implicate that the stronger conjoint reference is not applicable.

Having sketched a pragmatic account of some aspects of control in English, I now want to retreat to a somewhat more moderate position. A theory that held that control was purely pragmatic would have to demonstrate that controlled co-reference links were in all cases defeasible. This is fairly clearly not the case: John wants to go does not, it seems, merely implicate, rather it seems to entail that John desires that he, John, go; it seems difficult to find a contextual scenario able to defeat that interpretation. ${ }^{45} \mathrm{I}$ assume that control in English is indeed partially grammaticalized, although probably less so than is currently presumed - which is a matter that deserves more careful investigation. What is interesting, in the current perspective, is that the grammatical patterns follow the patterns predicted by our pragmatic apparatus: minimal forms prefer coreferential readings, less minimal forms prefer disjoint readings. Thus grammar may, in some respects, be treated as 'frozen pragmatics'. This, of course, would be especially convincing if we could show

[44] Since (a) PRO would fall afoul of the 'equal lexicalization' constraint, and (b) PRO is, arguably, a gap rather than an abstract item with meaning.

[45] It is clearly possible here for PRO to be not strictly co-referential, but merely overlapping in reference, as e.g. in the following exchange:

A: 'Who else wants to go to the beach?'

B: 'John wants to go'

where the interpretation may be 'John wants us (including him) to go'. This is however a quite general possibility for what we have been calling co-referential readings, and thus for the Binding Conditions (Higginbotham, 1983). Nevertheless, this possibility is not open in the co-referential readings grammaticalized by Binding Condition A - reflexives do not have this flexibility of interpretation (ibid. 400). Thus the possibility of overlapping reference may be a touchstone for partial pragmatic resolution of co-reference, suggesting that although John wants 10 go may entail 'John desires that he, John, go' there is no reverse entailment. 
that what is a (partially) grammaticalized pattern in one language is a purely pragmatic pattern of preferred interpretations in another. It is to this that we now turn.

\subsection{Pragmatic account of anaphora in Guugu Yimidhirr}

We detailed some aspects of Guugu Yimidhirr anaphora above (Section 2) by comparing them to the Binding and Control accounts of English. Despite the contrasts between the languages, and the lack of much of the grammar of anaphora distinctive of English, there are, we noted, some very similar patterns of preferred interpretation. From the discussion of English, it should be fairly clear how our pragmatic principles can be used to account for those patterns, so the discussion can be brief. However, unlike in English, where a pragmatic account may be partly eclipsed by a grammatical explanation, in Guugu Yimidhirr the grammatical contribution to the patterns is minimal, and the pragmatic account will be essential.

4.2.I. Guugu Yimidhirr Binding. We noted that there is an analogue to Binding Condition A given by the Guugu Yimidhirr anti-passive/reflexive. Since the use of that verb form reduces the nuclear valents by one, the Guugu Yimidhirr analogue to GB 'anaphors' is necessarily a clause-bound phenomenon. This antipassive/reflexive construction is central to the grammar of anaphora in Guugu Yimidhirr, although 'co-indexing' is not entirely grammaticalized even here as the reflexive/reciprocal reading is pragmatically selected from the alternative (accidental/unknown agent) readings.

The pragmatic account of the Guugu Yimidhirr Binding facts would go as follows. There is a clear contrast set formed by the alternate verb inflections, antipassive/reflexive vs. active, setting up a Horn-like scale over the morphemes 〈REFLEXIVE, ACTIVE〉 (realized for past tense, in some conjugations, as $\langle-d h i,-y\rangle)$. For example:

(64) (a) ngayu gunda-dhi

$$
\begin{array}{ll}
\text { I-NOM hit-REFL+PAST 'I hit myself' } \\
\text { (b) ngayu gunda-y } & \\
\text { I-NOM hit-PAST } & \text { 'I hit (someone)' }
\end{array}
$$

(Notice that the object NP need not surface in (b)). So use of the (b) sentence will Q-implicate that the more informative (a) does not obtain. This will induce, as in English, the familiar complementary pattern, with pronouns (and gaps) within clauses being given a non-co-referential reading. However, where pronouns cannot be in contrast with the antipassive/reflexive, i.e. in any non-nuclear thematic role or grammatical function, there will be no Q-implicature to disjointness. Thus nhangu, ' 3 rd. sing. animate-GEN-ABS' in the sentence below could not be expressed by any reflexive form:
$(65)$
John-ngun nhangu
John-ERG he-GEN-ABS
biiba father-ABS hit
'John hit his father' 
Given which, I-enrichment to co-referentiality will take place linking 'John' to nhangu ('his'), unless this is inconsistent with what is taken for granted.

Notice that, as far as I can see, the configurational constraints that operate to make a c-commanding NP in English a preferred antecedent for a pronoun do not operate in Guugu Yimidhirr. An important question, of course, is whether there are, nevertheless, some non-configurational analogues to them. It is a question not perhaps so easily answered. Consider:

$\begin{array}{lll}\text { nyulu biiba } & \text { John-bi } & \text { gunday } \\ \text { He-NOM father-ABS } & \text { John-GEN + ABS } & \text { hit } \\ \text { 'He hit John's father' } & & \end{array}$

Certainly this order (pronoun before lexical NP) predisposes to a nonco-referential reading between the pronoun nyulu ('him') and John, just as in English (cf. (54)(a) vs. (b)). It might be argued that this is the familiar configurational effect which motivates the c-command analysis of English co-reference possibilities. To capture this c-command-like configurational effect in a non-configurational (and non-constituency) language, we would have to frame a non-configurational (or non-constituency) analogue of Reinhart's second rule in (53) in terms of Theta-role or grammatical function, perhaps along the following lines: 'Grammatical co-indexing is permitted where a lexical NP in A- or S-function matches the person and number of a Genitive pronoun (or a pronoun not in O-function) in the same clause'. Since (66) does not meet this condition, grammatical co-indexing would not apply, and (66) would therefore be a misleading way to try to express the co-referential interpretation (if that is what the speaker meant, he should have reversed the pronoun and the name to meet the conditions for grammatical co-indexing).

However, against this argument for analogues to configurational effects, we may note what happens if we re-order (66) (recollect that Guugu Yimidhirr has almost entirely free word order):

(67)

\begin{tabular}{ll} 
nhangu-gu & \multicolumn{1}{c}{ John-bi } \\
he+GEN + ABS-EMPH & John-GEN + ABS \\
biiba nyulu & gunday \\
father-ABS he-NOM hit \\
'He hit his, John's father'
\end{tabular}

It is now less clear that co-reference (between nyulu ('he') and John) is ruled out, especially with the additional genitive pronoun and emphatic particle. If this is correct, then it suggests a linear order effect, and a wholly pragmatic rather than a partially grammatical explanation, but the phenomenon certainly needs further investigation. (If sheer order proves not to be the relevant issue, then recourse may still be had to Bolinger's (1979) idea that 're-identification' by full NP must be in the theme and not the rheme (which almost makes the right predictions for English too; see Reinhart, I983: 
$96 \mathrm{ff}$ ).) Either way, though, we need an account of why (65) invites a co-referential interpretation (either in terms of Theta-role or a purely pragmatic dimension like order), and an appeal to the Q-principle to explain why (66), by complementarity, resists such an interpretation.

If for the present we assume that we do not need Reinhart's boundanaphora rule (or any non-configurational analogue of it) for ordinary NPs, ${ }^{46}$ then the only rule of grammar we need to refer to is the reflexive. The pragmatic consequences of the availability of the reflexive will be that Q-implicatures arising from the 〈REFLEXIVE, ACTIVE〉 opposition (e.g. the opposition between the morphemes $\langle-d h i,-y\rangle$ ) will block I-enrichment just between NPs in A- and O-function in the same (active) clause.

The I-principle will therefore induce co-referential readings quite generally wherever the Q- (and Q/M) implicatures to disjoint reference are absent. Thus I-enrichment will coindex pleonastic pronouns with animate NPs in the same Theta-role or grammatical function. ${ }^{47}$ Notice that this can take place even when the pronoun and the lexical NP do not agree in person or number:

\begin{tabular}{|c|c|c|c|}
\hline (68) (a) & $\begin{array}{l}\text { John } \\
\text { John-ABS } \\
\text { 'John and the }\end{array}$ & $\begin{array}{l}\text { bula } \\
\text { 3DUAL-NOM } \\
\text { other chap came }\end{array}$ & $\begin{array}{l}\text { gaday } \\
\text { came }\end{array}$ \\
\hline (b) & $\begin{array}{l}\text { John } \\
\text { John-ABS }\end{array}$ & $\begin{array}{l}\text { ngandhaan } \\
\text { IPL-NOM }\end{array}$ & $\begin{array}{l}\text { gaday } \\
\text { came }\end{array}$ \\
\hline
\end{tabular}

This is reasonably frequent in Guugu Yimidhirr since there is no other way to express NP conjunction, and it reinforces the need (present in English too) for an account of co-indexing that allows for referential overlap rather than identity (see Higginbotham, 1983: 399 ff.).

There remains the problem of lexical NPs in Guugu Yimidhirr, which fail to meet the Binding Condition $\mathrm{C}$ not only because of the pleonastic pronouns, but also because a pronoun in c-commanding-like position over a lower clause, can 'bind' (be co-indexed with) a lexical NP in that lower clause.

[46] We may, though, still need something similar for quantifier-bound pronouns and gaps; for a possible E-type sentence see Haviland, 1979a: 104, example (191). Consider for example the following (constructed) sentence:

$\begin{array}{lll}\text { dhana wulbu-umu-n gaarga } & \text { dhanaan } & \text { gunda-y } \\ \text { they-NOM all-mu-ERG y-brother-ABS } & \text { 3PL-GEN-ABS } & \text { hit-PAST } \\ \text { 'They all hit their younger brothers' } & & \end{array}$

To obtain the lambda-interpretation, 'they each hit their own younger brother(s)' we will need a rule that achieves the same effect as Reinhart's interpretive rule (1983: 159-160), but without requiring a configurational basis.

[47] Actually, there are reasons to think this will be achieved by the semantics, which in Guugu Yimidhirr with its free word order will have to coindex all words whose case-inflection identifies them as distributed parts of a single valent. If so, the pragmatic argument is merely redundant. 
Example ( $16 \mathrm{~b}$ ), repeated here, apparently has an emphatic quality, but it was freely offered by an informant:

$\begin{array}{llll}\text { John-ga-m-un } & \text { biiba-ngun } & \text { nhangu } & \text { gurray } \\ \text { John-GEN-m-ERG father-ERG } & \text { he-DAT } & \text { said } \\ \text { 'John's father told him } & & & \end{array}$

$\begin{array}{clll}\text { [John-ngun } & \text { nyulu nhayun } & \text { balga-nhu] } \\ \text { John-ERG } & \text { he-NOM it-ABS } & \text { make-PURP } \\ \text { that John } & \text { should make it' } & \end{array}$

But this possibility is expected given the inapplicability of Reinhart's bound-anaphora rule in Guugu Yimidhirr: there can be no Q-implicature to non-co-reference from the non-use of a (non-existent) stronger boundanaphora sentence. What will remain is a $\mathrm{Q} / \mathrm{M}$-implicature from the use of a marked form (full lexical NP) where a pronoun would induce co-reference by l-implicature: this might provoke a disjoint reading, but where, as here, the lexical NP matches an identical NP (John in John-gamun) already linked by I-enrichment to nhangu, it will be a better interpretation to seek a contrastive/ emphatic reading rather than a disjoint reading. The potential $\mathrm{Q} / \mathrm{M}$-implicature to disjoint reference is sufficient to account for the marked nature of examples like this, and to produce a pattern of preferred interpretation parallel to the English data, but where the latter has a partial semantic basis in the bound-anaphora rule.

As for zero anaphora in Guugu Yimidhirr, we have noted that this can occur in almost all locations (the apparent exception being O-NPs in purposive clauses with S-NP antecedents in the matrix; Haviland, I979a: 136). The I-principle will, as usual, favour co-referential readings for minimal forms (here, gaps); sometimes the antecedents for these gaps will not be core-NPs (i.e. not S-, A-, or O-NPs) but adjuncts, as in the following sentence where an NP in adessive case serves as antecedent for the subordinate zero subject (from Haviland's text Balinga.trs 92), in line with the most plausible interpretation (see also examples in Haviland, I979a: I38):48

$\begin{array}{ll}\text { nyulu } & \text { bidha } \\ \text { he-NOM } & \text { child-ABS }\end{array}$

bamaa-gal
people-ADESS

dubi bandyii-nhu

left look after + REDUP-PURP

$\mathrm{He}_{1}$ left the child ${ }_{2}$ with the people ${ }_{3}\left[\varphi_{3}\right.$ look after $\left.\emptyset_{2}\right]$

'He left the child with the people for them to look after it'

[48] For example, if the purposive clause had different content, another interpretation might be much more plausible:

nyulu bidha bamaa-gal dubi wadhin dhada-nhu he-NOM child-ABS people-ADESS left hunting go-PURP $\mathrm{He}_{1}$ left the child ${ }_{2}$ with the people ${ }_{3}\left[\phi_{1}\right.$ to go hunting]

'He left the child with the people so he could go hunting'. 
Where there is no clear antecedent an inference will be made to the best interpretation bearing tacit assumptions in mind - the interpretation may be indefinite, or be contextually assigned, as in the following example (from Haviland's text T84/7A. NEC: 392; see also Haviland, I979a: 124, I39, example (339)):

$\begin{array}{lll}\text { (71) nhayun naaybu wunay walu } \\ \text { that-ABS } & \text { knife-ABS lay like } \\ \text { minha } & \text { wagiinhu } & \\ \text { meat-ABS } & \text { cut + REDUP-PURP }\end{array}$

That knife was there [ $\emptyset$ to cut meat]

'That knife was there (for people) to cut meat with'

Where a marked form, a contrastive adjective like yindu ('the other(s)') or a full lexical NP, occurs, such I-enrichment to co-reference (in particular) may be blocked by a $\mathrm{Q} / \mathrm{M}$-implicature; and in the same way there are notable, though weaker, implicatures to disjoint reference where a pronoun is used following a co-referential zero. For example, in the following sentence (from Haviland's text Wurey6. trs: 479), the natural interpretation is that the two pronouns are non-co-referential:

nyulu nhayun gadaa nhangu
he-NOM that-ABS comes he-ACC/DAT
$\mathrm{He}_{1}$ comes $\left[\phi_{1}\right.$ to spear him $\left.{ }_{2}\right]$
'He came to spear him'

An interpretation that is, I think, theoretically open, if implausible is: ' $\mathrm{He}_{1}$ came in order that (someone ${ }_{2}$ ) spear him $_{1}$ ' (compare for example the second clause of (26) above, glossing 'Don't tell him, that (someone ${ }_{2}$ ) is going to send $\mathrm{him}_{1}$ down South'). But the second overt pronoun, Q/M-implicating disjoint reference, strengthens the plausibility of the other reading, as of course does I-enrichment of the zero NP. ${ }^{49}$

Turning now to the issue of NP-gaps and control, we noted in 2.3.2 that although there are some parallels to control predicates in English, the evidence points to the absence of any special PRO-like empty category. Indeed, there is no evidence for any syntactic typology of gaps at all, as discussed in 2.3.3: first, there is no basis for a distinction between PRO (minus

[49] For another example of the tendency for successive pronouns to be non-co-referential see Haviland, (1979a: 155), example (413). There is another, essentially compatible, explanation of the pattern in examples like (72), namely: l-enrichment links the first 'he ${ }_{1}$ ' to the zero; then by the Q-implicature from the availability of the reflexive form, the zero and the second pronoun (glossed ' $\mathrm{him}_{2}$ ') should be disjoint in reference. However, if we take seriously the idea that Q- and Q/M-implicatures block I-implicatures, as outlined in the conditions in (46), then perhaps the $Q / M$ derivation should take priority: i.e. here the pronouns glossed ' him $_{1}$ ' and ' $\mathrm{him}_{2}$ ' will be presumed disjoint by $\mathrm{Q} / \mathrm{M}$-implicature prior to attempts at I-enrichment. But the issue of temporal processing or algorithmic priority is perhaps one that hardly arises at this elementary stage of investigation. 
case) and pro (plus case), since all argument positions are subject to case. Secondly, in a language with such free word order, there can be no reason to posit NP-movement (rather than random order base-generation), and consequently the motivation for a typology of gaps, and indeed the view of gaps as syntactic categories, is further undermined.

Still, the distinction between subject-control and object-control predicates follows the Foley \& Van Valin (1983) prediction: the subjects (A-NPS) of volitional/commissive predicates control the zero subjects (A- or S-NPs) of purposive clauses, while the objects (O-NPs) of directive predicates control the zero subjects (A- or S-NPs) of purposive clauses. In the latter cases, at least, it seems that the gap may be realized as an overt co-indexed NP, or both controller and controllee can be zeros. ${ }^{50}$ Given these facts, it appears likely that we do not need an independent theory of control in Guugu Yimidhirr: the semantics of the controlling predicate will dictate which argument of the matrix clause is the most likely antecedent for an I-induced co-referentiality with the zero in the subordinate clause, in the manner sketched for English (see discussion of (59) above). Where that NP in the subordinate clause is realized by an overt element, our pragmatic principles will predict a $\mathrm{Q} / \mathrm{M}$ inference to (or at least preference for) disjoint reference, and none of these constructions requires co-referentiality between matrix and subordinate clause arguments (contrast English constructions like try to $V P)$.

In trying to assess the degree to which control is a grammatical or a pragmatic matter in Guugu Yimidhirr, we may turn to the criteria suggested by Andrews (1985: 110): 'If a complementizer merely permits an omitted argument in its clause to be understood as co-referential with one in the matrix, without requiring omission and understood co-reference, we could say that the omitted argument was just an anphoric pronoun, ellipsed by the usual principles, which happened to be co-referential with an NP in the matrix'. That is, for grammatical control two conditions must be met: (a) obligatory omission of controllee; (b) obligatory co-reference between an NP in the matrix and the null NP in the subordinate clause.

With regard to obligatory omission, we have already noted that all types of Guugu Yimidhirr subordinate clauses permit overt arguments in all grammatical functions $(\mathrm{A}, \mathrm{O}, \mathrm{S})$. This is especially clear if the NPs are NOT co-referential:

[50] Haviland, (1979a: $135 \mathrm{ff}$.) gives a careful account of the appearance of gaps in purposive clauses, although his discussion does not always take different types of control predicate into account. He seems to consider some of these 'deletions' obligatory, others preferential; however, some of those 'deletions' which he considers mandatory, e.g. with verbs of ordering, appear 'undeleted' in my data (see e.g. (24b), (69) above), suggesting that in general 'deletion' is a preferential rather than obligatory matter, with consequences to be discussed below. Only further work, though, will firmly establish the extent to which these patterns are grammaticalized. 

(73)
ngayu wawudhirr
Is + NOM soul-COMIT
'I want [you to eat]'
nyundu
buda-nhu
you + NOM
eat-PURP

(in contrast, directive object controlling predicates may require co-reference across clauses). However, even where co-referentiality occurs between controller and controlled NP, omission is not obligatory, - as indicated by ( $\mathrm{I} 6 \mathrm{~b}$ ) and other examples above, or by:

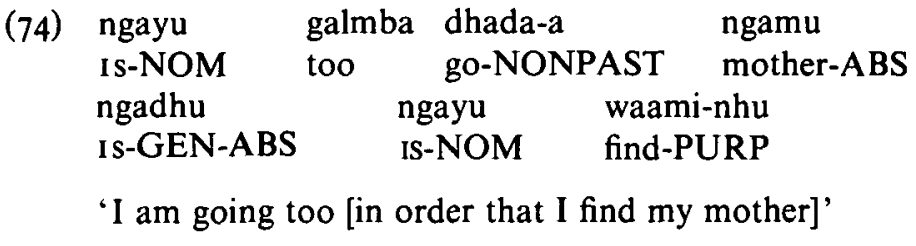

With regard to obligatory co-reference, as illustrated in the prior paragraph there is no such requirement in purposive clauses. This is hardly surprising, because any matrix clause can take a purposive clause (sense permitting), just as any clause can take an adjunct purposive NP (to which purposive clauses are parallel). For example (from Haviland, I979a: 135):

(75)

\begin{tabular}{lll} 
nyulu & yugu & \multicolumn{2}{c}{ baaway } \\
he-NOM & wood-ABS & \multicolumn{2}{c}{ burnt } \\
[nyundu & mayi & buda-nhu] \\
you-NOM & food-ABS & eat-PURP
\end{tabular}

'He lit a fire so that you could eat food'

Thus on Andrews' criteria there is no control in Guugu Yimidhirr, merely discourse zero-anaphora. There is further evidence of the lack of grammaticalization, as reviewed above in 2.3.2, provided by the facts that (a) the controller can be missing, (b) the controlled NP has ordinary case-marking if overt, (c) nearly all the so-called subordinate constructions in Guugu Yimidhirr, including the purposive, CANOCCUR AS MAINCLAUSES. Our pragmatic theory will fill the gap left by the evaporation of a grammatical account of control..$^{51}$

What I hope to have shown is that, given the pragmatic principles adduced, there is no need to suppose that there is much GRAMMAR of anaphora in Guugu

[51] This is not to deny the existence of some grammatical constraints of a control-like nature; as mentioned, Haviland, (1979a: 136) describes the resistance to deletion of objects of purposive clauses under identity with a matrix S-NP. He also notes (I $40 \mathrm{fr}$.) a most interesting constraint operative in another kind of 'subordinate' clause expressing simultaneous events, which can best be stated in terms of 'subject' (NPs in A or S function): where the subject of the subordinate clause is co-referential with the object of the matrix clause, the verb has the suffix -:yga; where the subject is co-referential with the matrix NP in A-function, it must take -nhun. Schematically:

$[A \ldots O]\left[\mathrm{A}_{2} / \mathrm{S}_{2} \ldots\right.$...:yga] where $\mathrm{O}=\mathrm{A} 2 / \mathrm{S}_{2}$

[A...O] $\left[\mathrm{A}_{2} / \mathrm{S}_{2} \ldots\right.$.. -nhun] where $\mathrm{A}=\mathrm{A} 2 / \mathrm{S}_{2}$. 
Yimidhirr. There appears to be no need of, or evidence for, Binding Conditions B and C, nor for Reinhart's Bound Anaphora rule; and no need for a special theory of Control, assuming just that the verb semantics predisposes to certain favoured interpretations. Given the reflexive/antipassive and its Q-implicatures, and the semantics of 'control'-predicates, the rest of the anaphora patterns, despite some parallels to English, can be best accounted for (given their preferential, defeasible nature) by our pragmatic apparatus, or something along similar lines.

\section{Conclusions}

I have outlined a set of pragmatic principles that are independently motivated in two ways: (a) they seem required to account for a broad range of pragmatic inferences (as illustrated in Section 3 above); (b) they can be seen to operate in conversation (see Levinson, 1987). These principles seem to have direct application to patterns of anaphora, where their interaction accurately predicts quite complex pattern of preferred interpretation (generalized conversational implicatures). These same patterns of interpretation seem to show up in the grammar of anaphora, suggesting something less than a sharp borderline between so-called 'discourse anaphora' and 'grammatical anaphora', and making potentially possible a wholesale pragmatic reduction of many aspects of the alleged grammar of anaphora.

Whether this suggests that large parts of what had been thought of as grammar should be shifted over into pragmatics, or whether more moderately we should view certain grammatical processes as 'frozen pragmatics' is a matter for debate. (Neither option will be especially palatable to Government and Binding theorists of course, who wish to see grammatical processes as sui generis.) One basis on which to make the decision is the exceptionlessness of the inferences: preferred interpretations must have exceptions; where there are exceptions, even if few and strained, we must suspect a pragmatic source (for the contrary view, see Chomsky, I981:227, fn. 45). And on this criterion, both Binding Conditions B and C (see counter-examples in (56) above), and many aspects of Control Theory (see counter-examples in (59)) look less than fully grammaticalized, even in English and certainly in Guugu Yimidhirr with its great syntactic flexibility.

A strong argument for the view that grammatical processes may have their sources in pragmatic processes comes from the comparison of two very different languages like Guugu Yimidhirr and English: what is preferred interpretation in one language may be grammar in the other. Such a view, which looks at gaps as the logical extension of a pragmatic principle of minimization, is of course somewhat at odds with a view that sees gaps as windows on the mind, as expressed in the following passage (Chomsky, 1982: 19): 
The properties of gaps are intrinsically significant in that the language learner can confront little direct evidence bearing on them, so that it is reasonable to assume that they reflect deeper principles of UG [Universal Grammar], the biologically determined endowment that will be the primary concern for those interested more in the nature of the human mind than in the arrangement of data in the environment.

But the I-principle, with its maxim of minimization, and its source in rational conversational cooperation, would seem to provide just the right kind of arrangement of data in the environment to make it possible for the language learner to acquire the felicitous use of NP-gaps without recourse to a specific biological endowment. Since the biological hypothesis, in the absence of direct neurological evidence, can only be an argument from the absence of any alternative plausible account, the attempt here to construct a pragmatic account of gaps and their interpretation should be of some general interest. ${ }^{52}$

\section{REFERENCES}

Andrews, A. (1985). The major functions of the noun phrase. In Shopen, T. (ed.), Language typology and syntactic description. Vol. I : Clause structure. Cambridge: Cambridge University Press. 62-154.

Atlas, J. D. (1975). Presupposition: a semantico-pragmatic account. Pragmatics Microfiche I.4. Di 3-GI4.

Atlas, J. D. \& Levinson, S. C. (1981). It-clefts, informativeness and logical form. In Cole P. (ed.), Radical pragmatics. New York: Academic Press. I-6I.

Bar-Hillel, Y. (1964). Language and information. Reading, Mass: Addison-Wesley.

Bar-Hillel, Y. \& Carnap, R. (1952). An outline of a theory of semantic information. MIT Tech. Report 247. Reprinted in Bar-Hillel, 1964: $221-274$.

Blake, B. (1983). Structure and word order in Kalkatungu: the anatomy of a flat language. Australian Journal of Linguistics 3. 143-75.

Bolinger, D. (1979). Pronouns in discourse. In Givon, T. (ed.) Discourse and syntax. Syntax and semantics, Vol. 12. 289-310.

Bouchard, D. (1983). On the content of empty categories. Dordrecht: Foris.

Charniak, E. (1972). Towards a model of children's story comprehension. MIT AI Lab Monographs, No. 226.

Chomsky, N. (1981): Lectures on Government and Binding. Dordrecht: Foris.

Chomsky, N. (1982). Some concepts and consequences of the theory of Government and Binding. Cambridge, Mass.: MIT Press.

Clark, H. \& Haviland, S. (1977). Comprehension and the given-new contract. In Freedle, R. (ed.), Discourse production and comprehension. Hillsdale, Erlbaum.

Cole, P. \& Morgan, J. (eds) (1975). Syntax and semantics 3: speech acts. New York: Academic Press.

Comrie, B. (1985).

Dixon, R. M. W. (1972). The Dyirbal language of North Queensland. Cambridge: Cambridge University Press.

Dixon, R. M. W. (1977). A grammar of Yidiny. Cambridge: Cambridge University Press.

[52] Postscript. In this paper, I have treated anaphora as an isolated problem. I do not believe that this is in fact quite the right approach. Reference tracking is a complex process, involving in particular the inference of clause linkage as well as referential dependencies. I have idealized the problem away from these other inferential issues simply for reasons of space and rhetorical force. A broader approach is sketched in Levinson, (1987). 
Dixon, R. M. W. (1979). Ergativity. $L g$ 55. 59-1 38.

Dixon, R. M. W. (1980). The languages of Australia. Cambridge: Cambridge University Press.

Dixon, R. M. W. (1982). Where have all the adjectives gone? Berlin: Mouton.

Dowty, D. (1980). Comments on the paper by Bach and Partee. In Kreiman, J. \& Ojeda, A. (eds.), Papers from the parasession on pronouns and anaphora, Chicago Linguistic Society. 29-40.

Evans, G. (1980). Pronouns. LIn II. 337-62.

Farmer, A. (1984). Modularity in syntax. Cambridge, Mass.: MIT Press.

Farmer, A. \& Harnish, M. (1987). Communicative reference with pronouns. In Papi, M., \& Verscheuren, J. The pragmatic perspective: proceedings of the international pragmatics conference, Viareggio, 1985. Amsterdam: Benjamins.

Foley, W. A. \& Van Valin, R. D. (1983). Functional syntax and universal grammar. Cambridge: Cambridge University Press.

Gazdar, G. (1979). Pragmatics: implicature, presupposition and logical form. New York: Academic Press.

Gazdar, G., Klein, E. \& Pullum, G. (1983). Order, concord and constituency. Dordrecht: Foris.

Gazdar, G., Klein, E., Pullum, G. \& Sag, I. (1985). Generalized phrase structure grammar. Oxford: Blackwell.

Geis, M. \& Zwicky, A. (1971). On invited inferences. $L$ In 2. 561-66.

Grice, P. (1975). Logic and conversation. In Cole \& Morgan (eds). 41-58.

Haiman, J. (1985). Natural syntax: iconicity and erosion. Cambridge: Cambridge University Press.

Hale, K. (1983). Warlpiri and the grammar of non-configurational languages. Natural Languages and Linguistic Theory 1. 5-48.

Harnish, R. M. (1976). Logical form and implicature. In Bever, T., Katz, J. \& Langendoen, D. T. (eds) An integrated theory of linguistic ability. New York: T. Y. Crowell.

Haviland, J. B. (1979a). Guugu Yimidhirr. In Blake, B. \& Dixon, R. M. W., Handbook of Australian languages Vol I. Canberra: ANU Press. 27-182. Amsterdam: Benjamins. 26-I 80.

Haviland, J. B. (1979 b). How to talk to your brother-in-law in Guugu Yimidhirr. In Shopen, T., Languages and their speakers. Cambridge, Mass: Winthrop. 16I-239.

Haviland, J. B. (n.d.) Complex referential gestures in Guugu Yimidhirr. Unpublished MS. ANU and Stanford Centre for the Advanced study of the Behavioural Sciences.

Heath, J. (1986). Syntactic and lexical aspects of nonconfigurationality in Nunggubuyu (Australia). Natural Language and Linguistic Theory 4. 375-408.

Higginbotham, J. (1983). Logical form, binding and nominals. LIn I4. 395-420.

Horn, L. R. (1972). On the semantic properties of the logical operators in English. Mimeo, I.U.L.C.

Horn, L. R. (1985). Toward a new taxonomy for pragmatic inference: Q-based and R-based implicature. In Schiffrin, D. (ed.).

Hudson, R. A. 1984. Word grammar. Oxford: Blackwell.

Jackendoff, R. (1972). Semantic interpretation in generative grammar. Cambridge, Mass: MIT Press.

Jespersen, O. (1924). The philosophy of grammar. London: Allen \& Unwin.

Kempson, R. 1975. Presupposition and the delimitation of semantics. Cambridge: Cambridge University Press.

Kempson, R. (1984). Anaphora, the compositionality requirement and the semantics-pragmatics distinction. NELS I4.

Kempson, R. (1985). Pragmatics, anaphora and logical form. In Schiffrin, D. (ed.), Meaning, form and use in context. Georgetown University Press.

Kempson, R. (to appear) Grammar and conversational principles. In Newmeyer, F. (ed.) Linguistics: the Cambridge Survey. Cambridge: CUP.

Kempson, R. (forthcoming) Logical form: the grammar cognition interface.

Koster, J. \& May, R. (1982). On the constituency of infinitives. $L g$ 58. 116-143.

Langacker, R. W. \& Munro, P. (1975). Passives and their meaning. $L g$ 5I. 789-830.

Levinson, S. C. (1983). Pragmatics. Cambridge: Cambridge University Press.

Levinson, S. C. (1987). Minimization and conversational inference. In Papi, M. \& Verscheuren, J. (eds.) The pragmatic perspective: Proceedings of the International Pragmatics Conference. Viareggio, 1985. Amsterdam: Benjamins. 
Lichtenberk, F. (1985). Multiple uses of reciprocal constructions. Australian Journal of Linguistics 5. 19-41.

Mohanan, K. P. (1983). Functional and anaphoric control. LIn 14. 64 I-74.

Popper, K. (1959). The logic of scientific discovery. London. Hutchinson.

Radford, A. (1981). Transformational syntax. Cambridge: Cambridge University Press.

Reinhart, T. (1983). Anaphora and semantic interpretation. London: Croom Helm.

Riemsdijk, H. van \& Williams, E. (1986). Introduction to the theory of grammar. Cambridge. Mass.: MIT Press.

Sacks, H. \& Schegloff, E. A. (1979). Two preferences in the organization of reference to persons in conversation and their interaction. In Psathas, G. (ed.) Everyday language: studies in ethnomethodology. New York: Irvington. I 5-2 I.

Schiffrin, D. (ed.) (1985). Meaning, form, and use in context: linguistic applications. Washington, D.C.: Georgetown University Press.

Silverstein, M. (1985). On the pragmatic poetry of prose: parallelism, repetition, and cohesive structure in the time course of dyadic conversation. In Schiffrin (1985). 181-99.

Simpson, J. \& Bresnan, J. (1983). Control and obviation in Warlpiri. Natural Language and Linguistic Theory I. 49-65.

Smith, N. V. (ed.) (1982). Mutual knowledge. New York: Academic Press.

Sperber, D. \& Wilson, D. (1982). Mutual knowledge and relevance in theories of comprehension. In Smith, N. V., (ed.). 6I-85.

Sperber, D. \& Wilson, D. (1986). Relevance. Oxford: Blackwell.

Wilson, D. \& Sperber, D. (198I). On Grice's theory of conversation. In Werth, P. (ed.), Conversation and discourse. London: Croom Helm $155^{-1} 78$.

Xu, L. (1986). Free empty category. LIn 17. 75-93.

Zipf, G. K. (1949). Human behavior and the principle of least effort. Reading, Mass.: Addison-Wesley.

\section{Appendix I. Guugu Yimidhirr text corresponding to gloss in example (2) in text}

The text is transcribed in the practical orthography described in Haviland (1979a), with a partial morpheme gloss as follows. Lexical NPs are in the absolutive (zero-realized) case unless marked otherwise, and pronouns are in the nominative case unless marked otherwise. Other cases are marked as follows: $A C C=$ accusative, $E R G=$ ergative, $L O C=$ locative, $I N S T R=$ instrumental, DAT $=$ dative; other glosses are: $P A R T=$ particle, $A S P=$ aspect marker, PAST $=$ past tense marker, REFL $=$ 'reflexive'/antipassive marker, $P L=$ plural, REDUP indicates reduplicated morph.

Gestures in the right-hand column have the approximate position of their 'acme' indicated by the symbol in the verbal transcript. Directional gestures are indicated by the customary abbreviations of the cardinal points; iconic gestures have the probable significance indicated in double quotes.

From Reveng I. mrg: dhana-:gu miil nhaa-dhaadhi gurra ${ }_{3}$ PL + NOM-EMPHeye-ABSsee-REFL + PAST also They looked at each other

garrbaadhi gurra. garrba-adhi gurra

hold-REFL + PAST and

Then they grabbed each other

I69 \{warra nyulu yii- \{you know warra nyulu yii you know old 3 SNOM this Old - you know 
I70 bama nyulu nhayun warra yabarraban bama nyulu nhayun warra yabarraban man 3 sNOM that + ABS very giant That chap was really gigantic

171 R: yabarraban. gu yabarraban-gu giant-EMPH A real giant.

172 bama nyulu dyimili-wi gaarga bama nyulu dyimili-wi gaarga man 3sNOM Jimmy Lee-DAT younger brother He was Jimmy Lee's younger brother

173 B: yeah (.) (maani yindu yeah maani yindu get-PAST other-ABS

Yeah. He grabbed one of them

174 dalmba-gabay $\{(1.0)$

\{'box'

dalmba-gab-ay

wrestle-zap-PAST

and threw him

$175 \mathrm{R}$ : yindu dalmba-gabay yindu dalmba-gab-ay

other-ABS wrestle-zap-PAST

Then he threw one of them!

176 B: \{yindu dalmba-gabay wel byindu dalmba-gab-ay other-ABS wrestle-zap-Past Right! Then he threw another

177 \{bulii-bulii galmba you know bulii-bulii galmba you know also

Bulii-Bulii was also you know,

178 \{ngaanaarru (warra $=$

ngaanaarru warra

whatchamacallit very

what do you call it?

$179 \mathrm{R}$ : = helpless

helpless eh?

I80 B: (helpless nhaadhi

helpless nhaa-dhi

\{'pick up \& dump'

\{points down $\mathrm{N}$

Yeah, helpless

I8I R: aa

Yeah

I

I82 B: \{nhangu maani

nhangu maani

\{'pick up \& dump'

3sACC get-PAST

He (Douglas) took him (Bulii-Bulii)

\{'empty hands'; \{shoulder jogs 
PRAGMATICS AND THE GRAMMAR OF ANAPHORA

183 nhangu galmba dalmba-gabay

nhangu galmba dalmba-gab-ay

3SACC also wrestle-zap-PAST

and threw him too

184 by the time nhangu (nhayun gundaarnday \{points down $\mathrm{N}$

by the time nhangu nhayun gund-aarnd-ay

3SACC that + ABS hit-REDUP-PAST

While he (Douglas) was hitting that third chap

I85 nyulu nhila (yii bama dyibaarr

nyulu nhila yii bama dyibaarr

3sNOM now this man South + ALL

He (Bulii-Bulii) this chap to the South

186 dabaarr-manaadhi

dabaarr-manaadhi

good-become-PAST

came to

$187 \mathrm{R}:$ \{yandaygu?

yand-ay-gu

arise-PAST-EMPH

Did he get up?

188 B: yanday (marrgin nhanmay

yanda-y marrgin nhanma-y

rise-PAST gun-ABS take-PAST

He got up and grabbed a gun

189 (marrginda gunday

marrgin-da gunda-y

gun-INSTR hit-PAST

He (Bulii-Bulii) shot him (Douglas) with the gun

\{nods S

\{points down $\mathrm{S}$

: iii

wow!

Ahah!

[

19I B: $\{$ (oof) (.) (ganaa budhu

ganaa budhu

\{'collapse'; ;"collapse'

Bang! alright intensifier

Bang! Okay then

192 R: badhaadhi

badha-adhi

finish-PAST

That finished him

193 B: \{yirngaadhi gurra

yirnga-adhi gurra

encircle-PAST and

\{'fumble around \& find"

\{'hold gun'

They stood around him (Douglas)

bulii-bulii-ngun (nambal maani

bulii-bulii-ngun nambal maani

\{points N

Bulii-bulii-ERG stone get-PAST

Bulii-bulii took a stone

I94 R: \{dumu baydyarrin

dumu baydyarr-in

\{'gather around"

chest-ABS crush-PAST

(B gestures 'throw down'

He crushed his chest 
195 B: ((Bangs chest))

$196 \quad\{(2.5)$

I97 B: \{miidaarrin

miidaarr-in

lift-PAST

They lifted him

198 maandi guwaalu

maandi guwaalu

take+PAST West-LOC

and carried him away to the West \{'crushes chest'

\{empty hands 'finished'

\{'lifting'?

\{arm slowly raised to point $\mathrm{W}$

$\begin{array}{llllrl}\text { \{nhayun } & \text { gala }\{\text { guwagu } & \text { birrii } & \text { nhayun maynggu } & \{W ;\{W \text { edge of } \\ \text { nhayun } & \text { gala guwa-gu } & \text { birrii } & \text { nhayun maynggu } & \text { river bank } \\ \text { that-ABS } & \text { far } & \text { West-LOC-EMPH river-ABS that-ABS mango tree } & \end{array}$

$\begin{array}{ll}\text { wunaarna } & \text { bada } \\ \text { wunaa-rn-a } & \text { bada }\end{array}$

lie-REDUP-PRES down

far West to the river where the mango trees are

\section{Appendix 2. The general anaphora pattern: English example}

(Superintendent to Poirot)

'Don't you see, if he ${ }_{1}$ had done that, it might have been bluff. It wouldn't have been half so convincing. The person ${ }_{2}$ might say to himself, 'The old man $_{1}$ won't call the police in, no matter what he $e_{1}$ suspects'. But if the old gentleman ${ }_{1}$ says to him ${ }_{2}$ 'I've already spoken to the police, the superintendent has only just left'. Then the thief $f_{2}$ asks the butler $_{3}$, say, and the butler confirms that. $\mathrm{He}_{3}$ says, 'Yes, the superintendent was here just before dinner'. Then the thief $f_{2}$

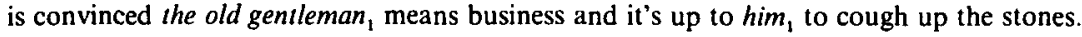

(Agatha Christie, Hercule Poirot's Christmas, Fontana, 1978: 64)

\section{Appendix 3. The general anaphora pattern: Guugu Yimidhirr}

We may use the extract in Appendix 1, with its English gloss in example (2) in the text, to illustrate the basic pattern we are trying to account for. The following note explains how the pattern is repetitively instantiated in the text.

The text starts with a pronoun dhana (3PL) referring to the four combatants collectively, the same reference being picked up by the reduced zero-form in 168 . In 169-170, the phrase warra nyulu, bama nyulu nhayun ('old he, the man he that one') is used to introduce a new focal referent, the co-referential phrase nyulu bama ('he the man') not being reduced further in I 72, I believe, because of the nature of the clause as an identity statement; but full reduction to (a co-referential) zero subject occurs in 173. There is a frequent pattern, to which this is an approximation, of progressive reduction from full lexical NP to pronoun to zero, implicating co-reference. The (absolutive) object of the transitive clause in 173 is a contrastive adjective yindu glossing 'the one', or on a second occurrence, 'the other'; this pattern is perhaps itself part of our anaphora pattern - repetitition of a non-minimal form will implicate disjoint reference. The zero subject continues to indicate co-reference through to line 177 where the full lexical NP (the name Bulii-bulii) implicates disjoint reference; in I82, a zero and a pronoun are interpreted so that the typical progressive reduction Name $>$ Pronoun $>$ zero is retained - the pronoun refers to Bulii-bulii, the zero to the earlier zero-subject. The same pattern is repeated in 183 , but in 184 we have a pronoun plus a demonstrative adjective nhangu nhayun (he-ACC that-ABS) - the fuller form Q/M-implicating disjoint reference with the previous pronominal object nhangu. We now switch reference from both the prior subject and object to a new subject in 185 by a full reference form nyulu nhila yii bama ('he now this man'), which $\mathrm{Q} / \mathrm{M}$-implicates reversion to Bulii-bulii as referent. Reference to him is continued in 186 to 189 by reduction to zero subject. And so on. Our general anaphora pattern is, despite occasional complexities, fairly clearly evident in this passage. 